\title{
Article \\ Green Interactive Installations as Conceptual Experiments towards a New Meaning of Smart Design
}

\author{
Anamaria Andreea Anghel ${ }^{1, *(1)}$, Diana Giurea ${ }^{1}$, Irina Mohora ${ }^{1}$, Alma-Dia Hapenciuc ${ }^{1}$, Octavian Camil Milincu ${ }^{1}$ \\ and Flaviu Mihai Frigura-Iliasa ${ }^{2}$ \\ 1 Architecture Department, Faculty of Architecture and Urban Planning, Politehnica University of Timisoara, \\ 300006 Timisoara, Romania; diana.giurea@upt.ro (D.G.); irina.mohora@student.upt.ro (I.M.); \\ alma.preda@student.upt.ro (A.-D.H.); camil.milincu@upt.ro (O.C.M.) \\ 2 Power Systems Department, Faculty of Electrical and Power Engineering, Politehnica University of Timisoara, \\ 300006 Timisoara, Romania; flaviu.frigura@upt.ro \\ * Correspondence: andreea.anghel@upt.ro
}

check for

updates

Citation: Anghel, A.A.; Giurea, D.;

Mohora, I.; Hapenciuc, A.-D.;

Milincu, O.C.; Frigura-Iliasa, F.M.

Green Interactive Installations as

Conceptual Experiments towards a

New Meaning of Smart Design.

Buildings 2022, 12, 62

https://doi.org/10.3390/

buildings 12010062

Academic Editor: Xianbo Zhao

Received: 6 December 2021

Accepted: 6 January 2022

Published: 9 January 2022

Publisher's Note: MDPI stays neutral with regard to jurisdictional claims in published maps and institutional affiliations.

Copyright: (c) 2022 by the authors. Licensee MDPI, Basel, Switzerland. This article is an open access article distributed under the terms and conditions of the Creative Commons Attribution (CC BY) license (https:// creativecommons.org/licenses/by/ $4.0 /)$

\begin{abstract}
Nature-based design process with its embedded concept of form that follows function can be materialized as products capable of incorporating aesthetics and functionality similar to the characteristics of its natural role models. The paper addresses the topic of green installations created through a design process that simulates nature's smart developmental mechanisms. The aim is to create an interactive installation capable of receiving and interpreting external factors that would determine the ensemble's behavior and influence its future development and evolution. The main challenge lies in the fact that the smart feature is often achieved by intensive use of technology, which often overshadows inventive ways in which the behavioral and aesthetic properties of the material can be reinterpreted. The interactive green installation "Modgrew" investigates the possibilities of obtaining smart features through the experimental testing of two main types of configurations. The results underline the fact that, by applying the principles of biomimetic design, technologies from different fields can be combined towards obtaining a smart product. The conclusions highlight the need for future studies cover subjects such as the efficiency of automation, the possible reconfiguration of modules, behavioral optimization over time, the identification of minimal tech alternatives and the reduction of maintenance necessities.
\end{abstract}

Keywords: modular installation; interactive mechanism; green technology; biomimicry; smart design

\section{Introduction}

Explored throughout history, the natural world is an infinite, omnipresent resource to which humankind has recurrently returned, looking for both inspiration and innovation. Oftentimes misaddressed as decoration, for it is the visible shapes and patterns that are rapidly perceivable, nature-inspired design is besides aesthetically pleasing, resilient, sustainable and a valuable engineering incentive. Research work in the field of Biomimicry, undertook by biologist Janine Benyus explores the potentiality of natural growth patterns and urges scientists to "learn from nature" [1], reaching into a deeper sense of knowledge than a simple visual examination of form. Nature serves as a model not only in the creation of shapes and patterns, but also as an overall approach method, offering versatile solutions through step-by-step processes [2], adaptable to solving complex challenges of humanity.

Nature alienation has characterized our lifestyles and planning strategies for several decades, the consequences are now visible in our global health condition and life choices. Severe cases of chronic illnesses or Sick Building Syndrome [3], are common features of modern society, workplaces and communities, thus enforcing radical changes in urban planning, architecture and design, that have been excluding nature in benefit of increasing real estate profit. 
Sustainable approaches are urging to reclaim urban nature, extending to intermediate spaces such as patios [4] and interior spaces alike [5]. The feasibility of green systems is an ongoing discussion in multiple fields, as implementation and maintenance costs often surpass those of end benefits, due to systems complexity, design, and implementation faults (greenery is often mistaken for decoration). Clear economic advantages are being emphasized by researchers, as green facades show thermic insulation properties [6] for the outer layer of building skins, while indoor vegetated systems increase indoor air quality and wellbeing [7].

Considering the above-stated ideas, the team has established a project with an openend theme to develop an "interactive living wall", as an optimization solution to existing green walls that overlook the natural character of vegetation, imposing robust, inadaptable systems that turn into decorative elements rather than emphasizing their organic nature. On an anthropological level, the subject is of major significance, emphasizing the benefits of a stronger human-nature connection [8] through natural processes on different levels of complexity, thus transforming green walls into attractive, interactive mechanisms that consider the dynamic necessities of the planted material. In light of modern lifestyles that oftentimes demand indoor activities and exceptionally confinement, bringing nature inside is mandatory for physical and mental wellbeing [9].

"Modgrew" is a multidisciplinary approach towards nature-inspired design, implying novel methods of collaboration between designers, architects, and engineers, with 3D printing technology, greenery, and education methods as common ground. Acknowledging the importance of teaching sustainability and innovative thinking in all fields, the team was brought together by principles that guided the study throughout: lessons from nature, natural engineering, technological solutions to support a new level of human-nature interaction.

Furthermore, allowing the theme to develop along the course of the project, opened new perspectives, leading to organic strategies that empowered the team members to use the acquired technological resources and knowledge, to become engaged in humanitarian actions outside the project.

\subsection{Lessons from Nature: Natural Engineering}

Theoretical substantiation, complemented by prior studies and experiments undertook by the team members, established an important foundation for the project development and goals. Modularity [10], sensory responsiveness, parametric design [11], environmental interaction, reflected through various executed prototypes, were valuable key components. Rather than defining finite products, the team opted towards creating "systems" that interact differently with environmental stimuli. This "bottom-up" approach has led to an organic development of methodologies and processes, creating dynamic relationships between project components.

Among the first steps, the team members have experimented with several humanenvironmental interaction typologies: tactile, kinetic, acoustic, or visual, leading to various shape alterations. The principle of kinetic architecture engages into a higher level of interaction and perception, generating sustainable solutions and direct analogies to the living world. Materialized into ephemeral installations, inserted into various contexts these practical studies paved the way to valuable conclusions regarding parametric form management, design and implementation.

Attempting to integrate natural elements into these system typologies, has generated a new series of challenges that demanded a more naturalistic approach. Thus, in light of existing studies on hygromorphosis, undergone by the Institute of Computational Design in Stuttgart [12], along with studies on climate-responsive architectural skins [13], the team has commenced experimenting with natural materials transformation in the presence of humidity and temperature variations. Hygromophic [14] and photomorphic [15] architectural systems have drawn researchers' attention, as potential means of response to exterior environmental actuators. 


\subsection{Modular Green Walls}

Analyzing existing green wall typologies through their historical development [16] as well as a detailed classification [17] based on studies undergone at the Technical University of Delft, Delft, The Netherlands by Dr. Marc Ottelé [18], permitted an overview of the systems, valuable observations and conclusions on well-functioning components and parts that needed improvements. As a result of these initial studies, the team has agreed on the importance of one determining principle that was going to shape the design process and the final result: modularity. The practical aspects of well-designed modular green walls [19] are advantageous in terms of flexibility of implementation, usage and maintenance; thus, an important part of the project was research towards identifying the optimal shape for the system module, one that would respond to alteration in shape and size, movement, rotation, while ensuring sufficient stability and correlation of the overall structure [20]. Sequential deformation processes of the base module were experimented, using paper folding techniques for physical modeling, parametric design software and 3D printed prototypes, until the result was reached.

\subsection{Academic Experimentation}

The design process involved a dynamic educational activity, integrating academical exercises along the way. Interior architecture students were introduced to modular design and spatial geometry in the early years of their academical formation, to understand the importance of continuity and irregularity of an actual design process. One of the proposed didactic methodologies focused on two stages of complexity: basic three-dimensional geometries studies and modeling, then more advanced geometrical shapes. The final scope of obtaining spatial free-standing structures allowed students to firstly understand the potential functioning of a single module, then its role in a spatial tessellation.

Overall student activity was of great importance to the presented research project, as current "green design" trends are frequently noticeable within academic projects, both as rational or subconscious choices; fact that has brought evidence once more, that this sustainable tendency should be strongly emphasized as part of the curriculum, through exploration of all of its complexity, not solely shape studies. Experimentation with novel materials, new perspectives over the usage of natural components, were subjects of research through multidisciplinary experimentation, observation, and interpretation of natural processes.

\subsection{Technological Solutions: Facilitating a New Level of Human-Nature Interaction}

The human-nature interaction is in a certain way facilitated by a dedicated humanmachine interface.

All automation features of the whole panel (irrigation, movements, power management, etc.) are controlled by a PLC, which is connected to a standard tablet PC, integrated in the structure. This tablet has a dedicated software which displays the main environmental parameters, the status of each commanded device, the sequence control of each piece of equipment and the management of the power (solar panels, batteries, inverters, etc.). The system can run in automatic mode as well as commanded by the human user, in order to have a sort of direct and natural interaction with the plants.

The human decision could be also limited or banned in case of wrong decisions (such as hyper irrigation, vandalism, etc.), some of the features could be blocked or could trigger even alarms to local law enforcement authorities.

The whole system is fully autonomous, all required electricity is produced by the solar cells, and stored in batteries, inverters being set to the standard $230 \mathrm{~V}$ AC voltage, for more flexibility, and, also, for power safety (in case of solar power malfunction, the whole panel could be directly connected to a simple $230 \mathrm{~V}$ AC domestic plug), having a very low consumption. 


\section{Materials and Methods}

Nature-based art is seen as a both contemporary and evergreen direction that has been consumedly used in design due to the beauty, functionality, science, ever-changing, ever-evolving features and, most of the times, mystery it involves.

Whereas nature as s source of pure adulation has been present since the very first sparks of human artistic tendencies by means of mimicry or transcription, its ways, mechanisms and evolutionary features have not only inspired art, but complex discoveries in fixed sciences, too.

Based on the two most used contemporary ways of referring to green installations, that is either in a pure artistic or in an ecologic manner, the intention of the team's academic experimental endeavors was to experiment with ways of intertwining these directions and creating a living, dynamic, interactive installation capable of both receiving and interpreting external factors, such as natural and human stimuli that would not only determine some of the mechanism's present behavior, but also influence the future development and evolution of the installation itself.

Thus, through the interaction, teamwork and design processes undertaken throughout the academic year of both university lecturers and some of their students, a complex experiment was to transform an idea into an actual interactive green installation within months. The results would not only create a dynamic installation named "Modgrew", but also pave the way for learning through experimentation within the Faculty of Architecture and Urban Planning in Timisoara, Romania.

Based on the general architectural faculty tendency of identifying and analyzing topics of potential social, cultural, functional, aesthetic, etc. problems, studying their characteristics and proposing knowledge-based solutions, in the past academic years there has been an increasing openness towards such voluntary endeavors within the Faculty of Architecture and Urban Planning in Timisoara, Romania. Whether they were teachersinitiated, part of the curriculum, or just voluntary experiments undertaken by students based on subjects that paved their thinking path in that direction (see Ecology, Natural Form Study, Ergonomics, Computer Aided Design, Parametric Design, etc.), a series of installations have furnished the faculty's hallways or the city's exterior spaces throughout last few academic years and local exhibitions or workshops.

The team has been involved in this at times spontaneous, yet continuous complex experiment, whether as students, or as teaching assistants. Therefore, the knowledge and experience gained by the team members during their previous academic and private experiments with parametric mechanisms and interactive panels open to external factors, would be the foundation of the design process of the proposed interactive green installation named "Modgrew". The whole project is a multidisciplinary one, involving a lot of aspects, from Architecture, Electronics, Arts up to Biology.

\section{Previous Own Experiments That Paved the Way for "Modgrew"}

\subsection{Academic Practice: Parametric Workshop}

The concept of the "Lacusta" installation (2011, Timisoara, Romania) was based on separating two different areas of the faculty's main hallway: the circulation and the sitting area by the window, the dynamic zone and the static zone, the semi-public and the semiprivate one. While experimenting for the first time with parametric design and digital tools (such as Grasshopper (Figure 1a), the name of the workshop being its actual translation into Romanian), this student-initiated workshop was held during a weekend, in which the design and manufacturing process have been finalized, in order to surprise the teachers with the installation on the next working day. The final result can be seen in Figure 1b-d. 


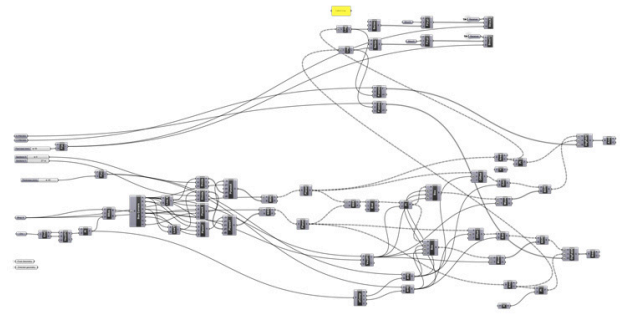

(a)

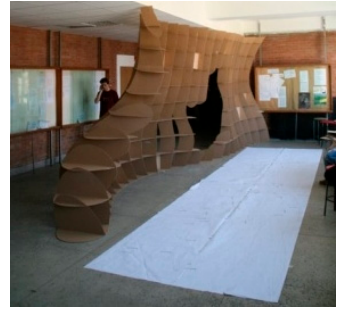

(b)

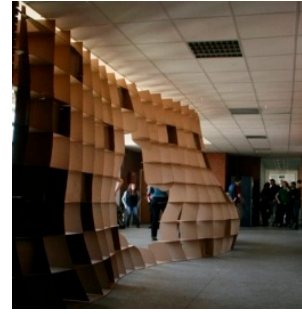

(c)

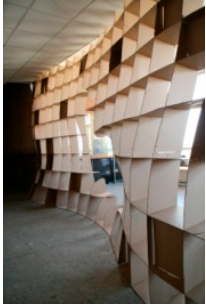

(d)

Figure 1. (a) Parametric definition; (b) Printed and executed installation cardboard layers; (c,d) The finalized installation. Team members: 4th Year Students of 2011, among which arch. Alma-Dia Hapenciuc.

This atelier is of interest for the entire process, as it describes both the level of initial knowledge, from which all team members have started, and their early interest in architectural installations.

\subsection{Private Practice: Parametric and Interactive Workshops}

In addition to seeking opportunities of implementing parametric ideas during academic activities, team members have simultaneously explored ways of introducing the concepts to private endeavors, being highly grateful for the open-mindedness of the "Flonta" Complex in Giroc, Romania, which agreed to invest in an interactive panel in 2014. Adding a new dimension to the previous experiment-the direct influence a user could have on the display of the modules that generated the installation-the materialization of the "moving" wall had a series of well-documented steps.

Firstly, the functioning diagram (Figure 2a) was developed, in order to internalize external input caught by a camera, which would be translated using the designed software. The reinterpreted dynamic image of the environment (Figure $2 b$ ) would then be transmitted to the actuators: servomotors that moved the modules, which, in that case, were square mirrors. Through this functioning mechanism, the wall consisting of those multiple square elements would become dynamic, mimicking the movement of the users in front of it in real time. Thus, we identified the possibility of an experimental functional diagram to become a communication platform between the environment and the installation itself. The interactivity, reflectivity and constant motion of the responsive wall (Figure 2c) inspired the team to further test ways of creating technological sculptures inspired by nature and its ways of developing itself.

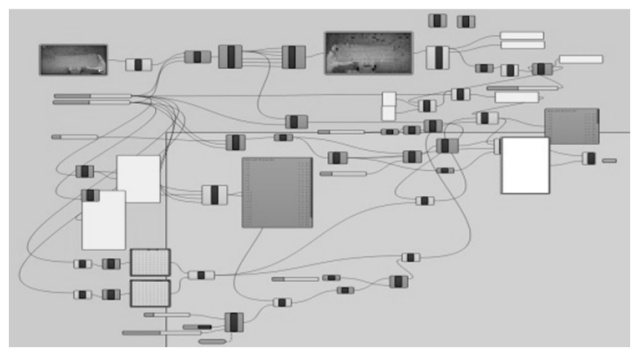

(a)

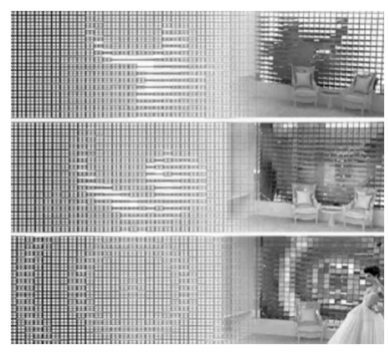

(b)

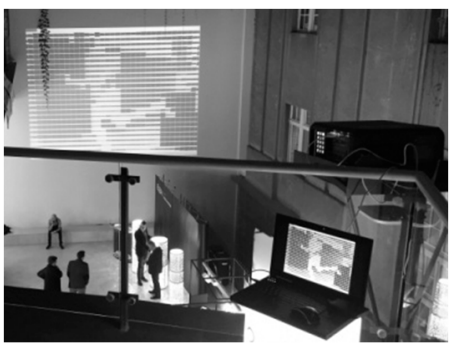

(c)

Figure 2. (a) Parametric definition; (b) Parametric change in visuals according to the movement in the environment; (c) Timisoara, Romania 2016 EDU Symposium Interactive Projection. Team members: arch. Adrian Mihai, arch. Alma-Dia Hapenciuc, arch. Oana Grecea.

\subsection{Academic Practice: Parametric and Nature-Inspired Workshops}

The open, playful, and artistic concept of the annual "Plai" Festival in Timisoara, Romania has made it possible for the faculty members and its promoters to repeatedly openly communicate and collaborate, in order to organize joint student workshops. Therefore, 
both the installation manufactured in 2015, and the one made in 2017, were designed by teaching assistants (among which arch. Diana Giurea) and materialized together with the students of the Architecture and Urban Planning Faculty.

Therefore, the "Hidden Nest Pavilion" was designed in 2015 as an entrance gate for the "Plai" Festival. Inspired by nature, the parametric organic shape was developed after researching the weaver bird's nest geometry. The digital design included the creation of a three-dimensional matrix (Figure 3a) and an organic subtraction that generated the gate's passage. Regarded as a successful installation, the "Hidden Nest Pavilion" opened a dialogue between a nature-inspired parametric installation and the people of Timisoara Figure 3b).

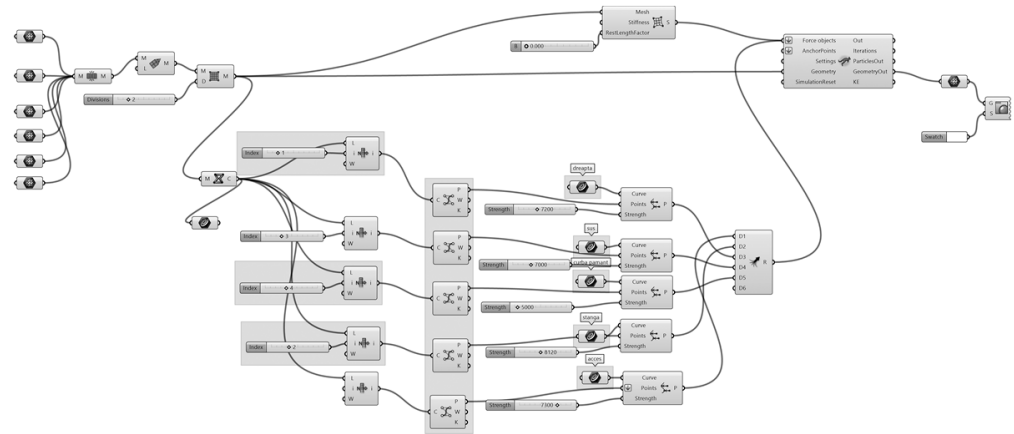

(a)

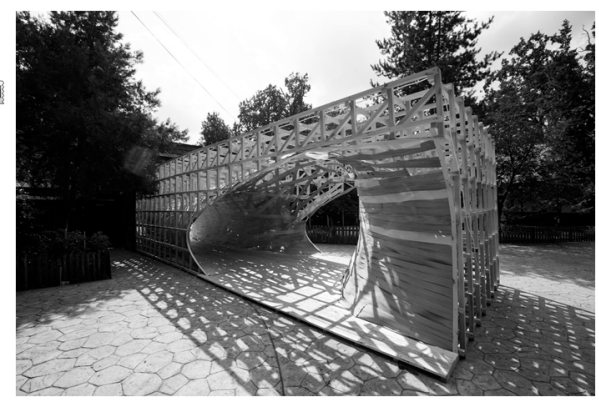

(b)

Figure 3. (a) Parametric definition; (b) The finalized installation. Team members: arch. Diana Giurea, arch. Zoran Popovici.

Furthermore, in 2017, the concept of the "Static Pulsation Wall" was being developed in the same context (Figure 4) [21]. Furthermore inspired by nature, namely the freedom of movement and dynamic of bird flocks, this installation added a new layer to the developing experience of the team members throughout their experiments, as it also considered the possible constant change of the installation, thus opening the dialogue about interactivity. While studying the functioning "mechanism" of the flock and the influence each bird has in the definition of its ever-changing geometry, the modeling process involved an actuator, for the first time, meaning that one of the modules of the installation would influence its entire resulting shape. Even though the interactivity was only used during the generation of the digital definition, the successive experimentation with iterations of the shape would subsequently be implemented as live features of the developed installations.

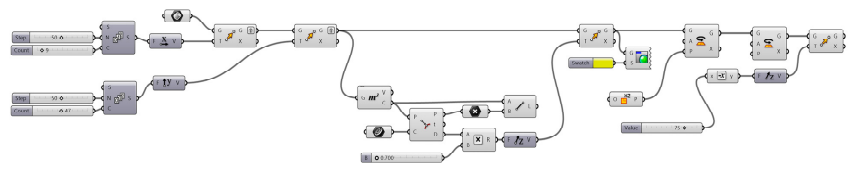

(a)

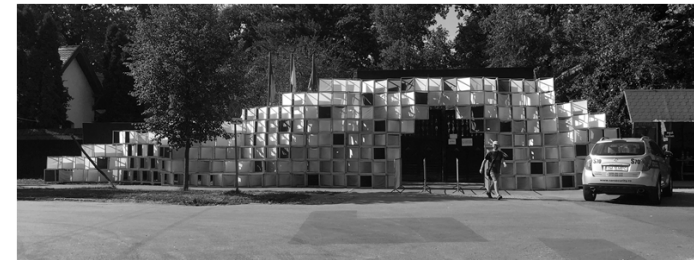

(b)

Figure 4. (a) Parametric definition; (b) The final installation. Team members: arch. Diana Giurea.

In conclusion, during these initial design experiments, the concepts of inspiration from nature, parametric design and module-based geometries have been among the team's interests. Other than workshops and seminars, the academic subjects the team has been part of at the Faculty of Architecture and Urban Planning in Timisoara, Romania have developed applications inspired by the architecture found in nature, by parametric or experimental design achieved by thinking outside of the box, such as Computer Aided Design, Form Study, Spatial Form Geometry, Basic Design, Fashion Design, etc. 


\section{Modgrew Installation}

\subsection{Environment Study and Basic Design Concept}

Following the research and study of installations that involved dynamics, naturalness and interactivity, the team directed its attention in 2018 towards developing an even bolder academic experiment.

Supported by the Faculty of Architecture and Urbanism, as well as the Politehnica University of Timisoara, Romania, through a research grant, it was possible for the team to implement and materialize their conclusions, which involved designing, sketching, programming and 3D printing parts of different concepts of dynamic installations inspired by natural evolution, capability of transformation and perpetual reinterpretation through the action of external stimuli.

Inspired by the two fundamental directions in approaching dynamic walls (ecological and artistic), the endeavor would be based on natural, green, environmental matters, as well as on human interaction directly connected to the mobility of the installation itself. Regarding the natural influence, "living" characteristics and the ability of embracing motion, actual physical transformation, and transition from one state to another, the communication with the human presence and external factors would be of the utmost importance. Therefore, the aim of the installation would be to become a dynamic, kinetic, and interactive mechanism designed to actively move according to the external stimuli it would receive.

In order for the academic endeavor to have a practical approach and influence, too, we started by analyzing Timisoara's openness towards new technology and innovative thinking. As of 2016, Timisoara gained the future title of European Capital of Culture in 2021 (delayed to 2023), which generated diverse cultural, social, infrastructural endeavors creating a conducive environment for innovation. Furthermore, the city invests in developing the local Multiplexity, a Center for Arts, Technology and Experiment, based on its traditional forward-thinking ability (see first European streets with electric lighting, first city of Romania using electric trams, first free Romanian city following the communist era and implicitly, the 1989 Revolution, etc.). Thus, introducing an interactive modular green installation to its public spaces would not be a far-fetched concept.

The evolution of the project also focused on ways of intelligently influencing public life towards a smart growth mindset, eco-friendliness, and interactivity. Therefore, we further developed the concept of green mechanisms in transportation nodes (tram or bus stations), in order for the interactive, living, vegetation filled installations to also encourage the decrease of greenhouse emissions, the increase of public transportation, by creating a lively, pleasant atmosphere [22] in sometimes darker, unsafe and shabbier areas, which do not emphasize communication and openness both between individuals and between the citizens and the public transportation network consisting of route information, arrival times, even a careful behavioral overall concept towards the public domain and public vegetation.

Following all previously described principles, our endeavor would consist of designing, programming, modeling, 3D printing and introducing an interactive installation to users (firstly focusing on the team and academic environment, and making successive tests, experiments and needed or requested improvements, secondly installing it in public areas). In order for more sides of the experiment to be taken into consideration, we organized our endeavor in different stages and small-scale concepts and projects, which will be described below.

\subsection{Initial Concept of the Interactive Green Installation Modgrew}

Based on the idea of encouraging everyday life and public transportation waiting times to direct interest towards an installation with educational, ecological, technological, yet ludicrous features, "Modgrew" would contain modules with containers for different plants and informational panels about both the features of the vegetation and the public transport (Figure 5a). The kinetics of the installation would rely on the external necessities of the plants (natural light, moisture), [23], which would be detected by the automation 
system programmed by the team, including sensors for motion, light intensity and humidity (Figure 5b) connected to servo-motor actuators that would enable the constant motion and transformation of the installation.

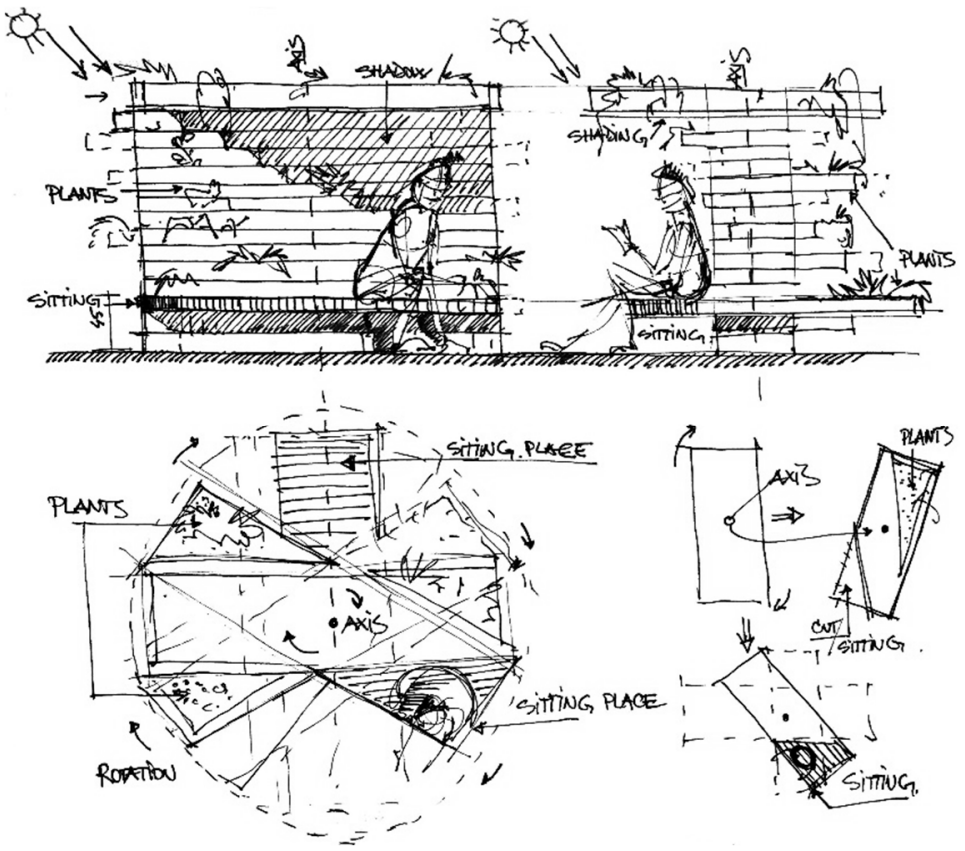

(a)

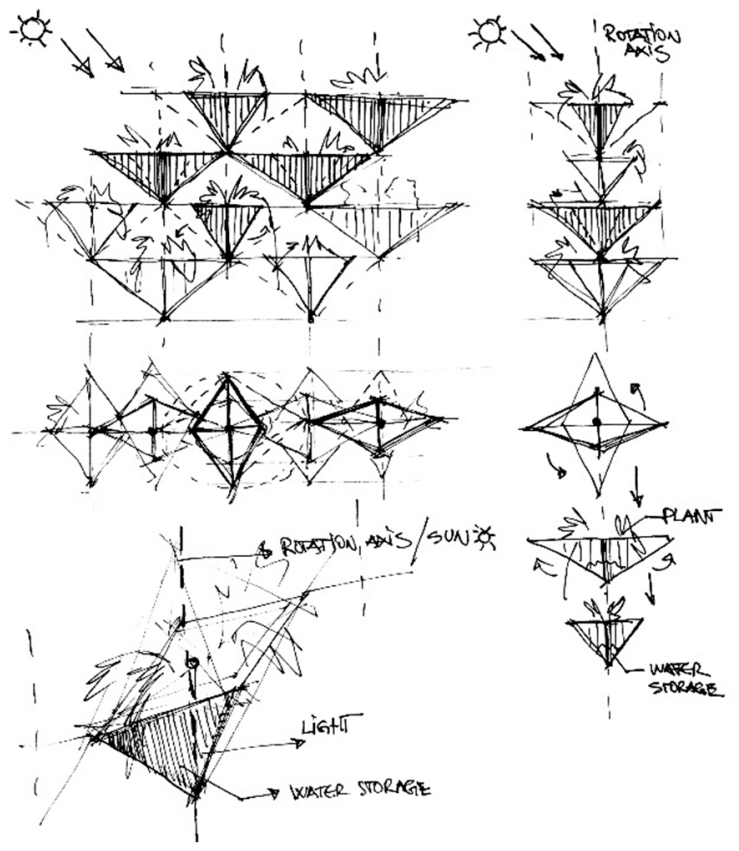

(b)

Figure 5. (a) Conceptual sketch of the interactive installation; (b) Conceptual sketch of the installation kinetic modules influenced by light and humidity.

Enabling automation to upgrade its features, the installation would thereby house diverse functions, such as informational point, sitting area, oxygen, and light source (during nighttime), additional green space in public areas, ludic mechanism inviting towards discovery, education and technological interactivity.

The motion principle of the mechanism is structured in two main response types. Principally, the sensors captured external and natural stimuli such as lighting, solar radiation, and humidity. They communicate the parameters to the main automation system, implemented by means of a dedicated software (inside a programmable logic controller-PLC, the entire system being powered by an $800 \mathrm{~W}$ photovoltaic panel, and, if necessary, by a connection to the public electricity network), who will activate the actuators (materialized by small servomotors) that enabled the movement of the structure's green modules. This programmed motion was intended to improve the life of the plants in urban areas by directing them towards the needed beneficial natural light for photosynthesis, respectively, warding them away from harmful solar radiation (and blocking it by activating the integrated shading panels), and also watering them using the incorporated irrigation system due to detecting low levels of air humidity as seen in Figure $5 b$.

Secondly, both educational and playful aspect of "Modgrew" focused on the influence the human factor may have on the esthetics of the installation itself. By using a web camera, it directed itself towards people that showed interest, it displayed necessary transport information, provided artificial light when needed, rotated according to the people's movement, respectively, sent messages and information regarding its own needs by using colored light (need for light, need for watering, etc.), or the needs of the city (signaling general information, such as levels of pollution or of vegetation), as on Figure 6 [21]. 


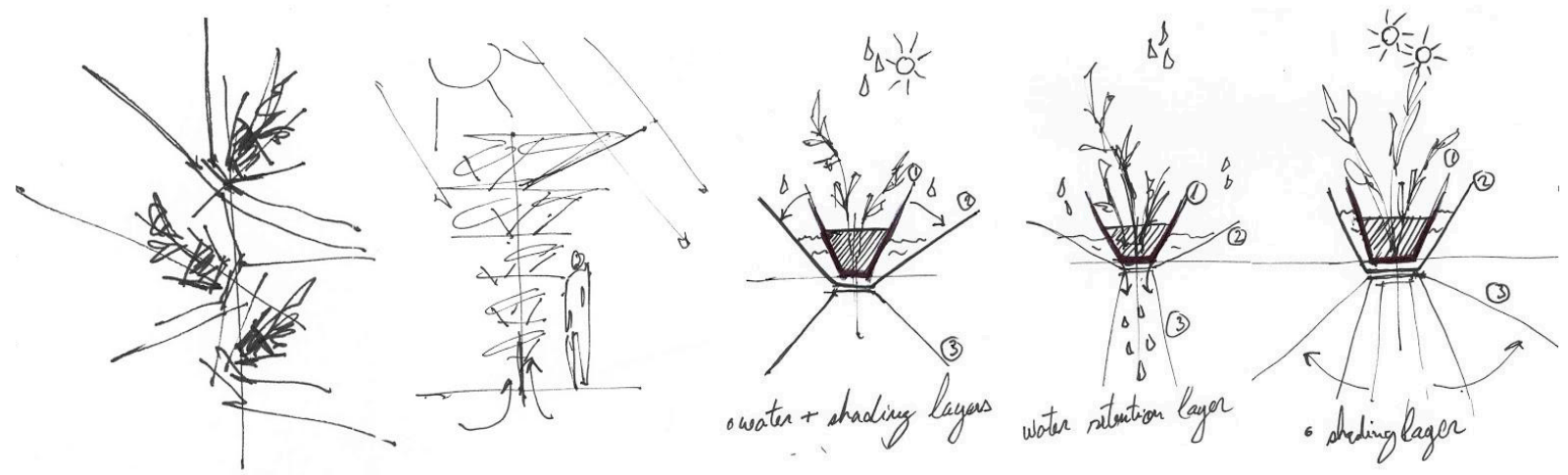

Figure 6. Conceptual sketch of the installation's kinetic responses to external factors, such as light and humidity.

This interactive communication platform was not only intended to benefit the wellbeing of the plants and the public transportation knowledge of the citizens, but to also open a young, locally unprecedented dialogue between people and kinetic mechanisms. An initial volumetric proposition for a modular system applied to public transportation units can be seen in Figure 7.
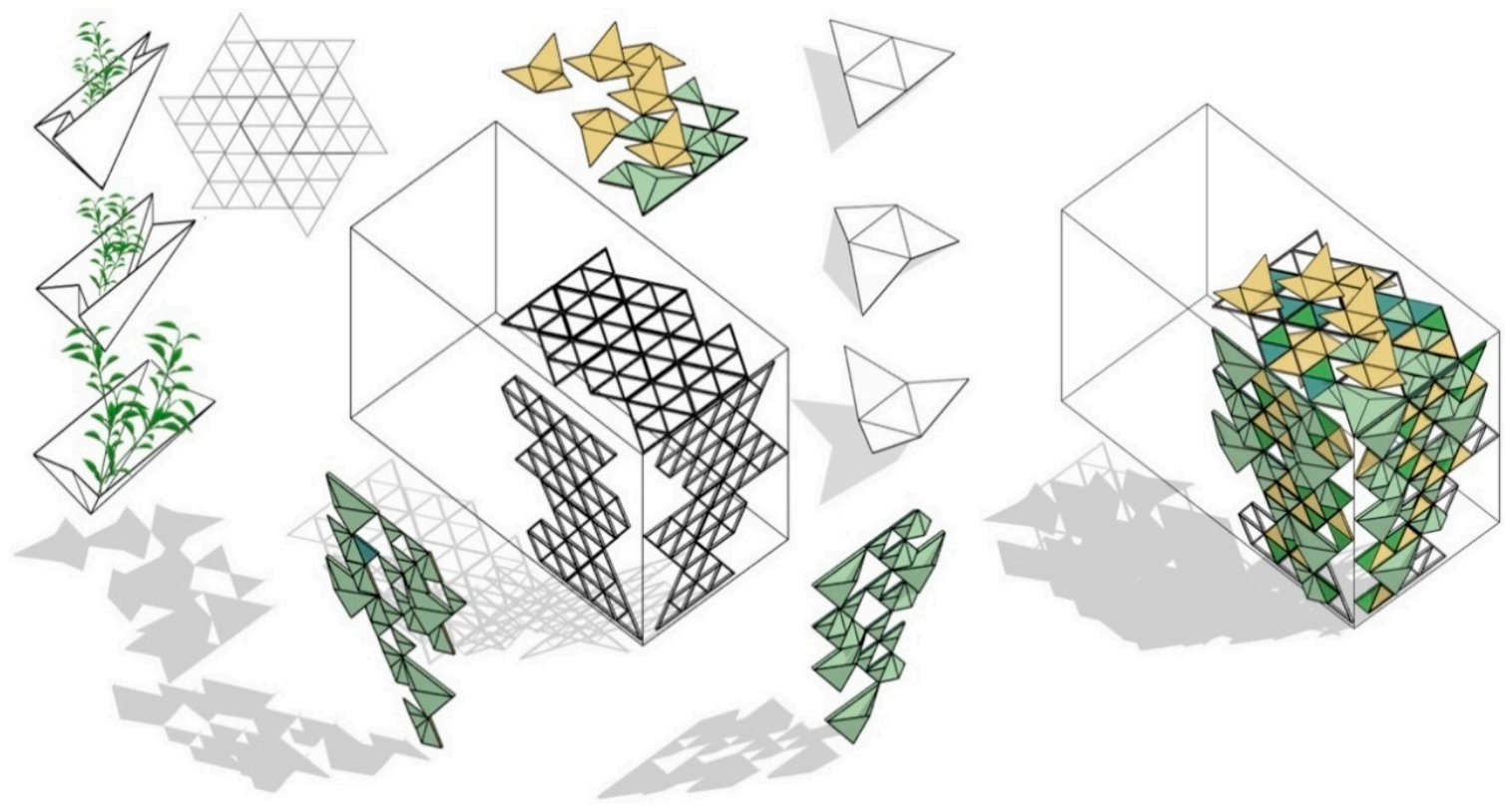

Figure 7. Digital materialization of the initial sketches regarding the green installation and its responses to external stimuli.

\subsection{Research Regarding Eco-Friendly Smart Design and Innate Material Features of Interactivity}

In the second part of the research, while questioning the actual premises of the concept, we directed our efforts towards an in-depth study of smart technology-based design. Was it possible for "Modgrew" to include all the initial conceptual features without heavily relying on state-of-the-art technology and implicitly, on diverse fabricated parts, which are part of global industries that continuously generate high levels of pollution? Was it not more feasible and environmentally friendly to return to local materials and existing knowledge that have similar capabilities but have been ignored in favor of attractive, new technologies?

Thus, an adjacent study emerged regarding independent responsive systems, which would not include any digital technology and automation [24]. We aimed to develop installations by putting aside apparatuses and emphasizing on certain materials that already had the innate ability of transformation due to external stimuli. 
The developed concept consisted of an array of composite lamellae, which, through the features of the material itself, would respond to external factors, such as environmental humidity levels and temperature variations. Choosing the simplest raw materials and studying how to put them in place in order to emphasize their natural dynamic features, the experiment included two different components. Firstly, we used Kapton tape [25] for its temperature sensitivity, whereas we secondly used hygroscopic materials, which do not show such openness to temperature changes (copy paper, package paper, watercolor paper, sycamore veneer of Kraft paper), as seen in Figures 8-18 [26].
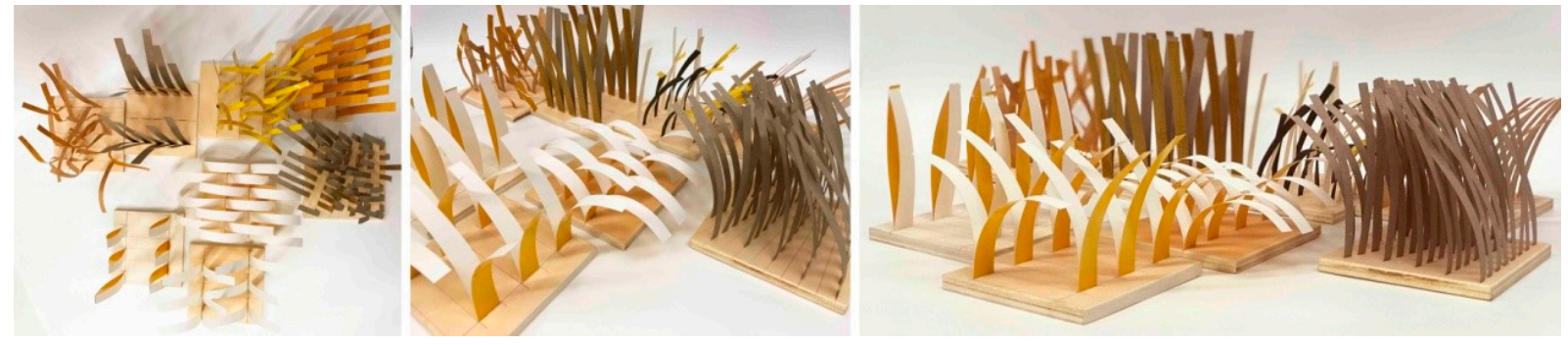

Figure 8. Models and samples changing their shape and inclination due to temperature variations.

The conclusions of the experimentation on diverse materials were directly linked to their responsiveness to temperature and humidity variations and to their ability to accordingly change their shape. Main Kapton tape properties are available on [25].
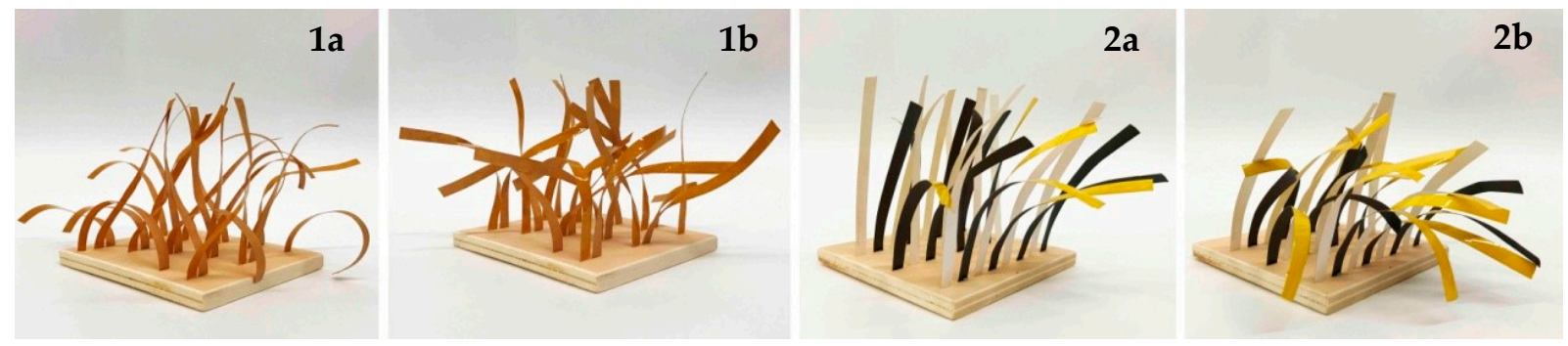

Figure 9. Kraft paper and Kapton tape (1a and $\mathbf{1 b})$, respectively, Copier paper, black ink and Kapton tape (2a and $\mathbf{2 b}$ ) and their shape change influenced by temperature variations, $18{ }^{\circ} \mathrm{C}(\mathbf{1} \mathbf{a}$ and $\mathbf{2 a})$ versus $50{ }^{\circ} \mathrm{C}(\mathbf{1 b}$ and $\mathbf{2 b})$-conclusion: failure.
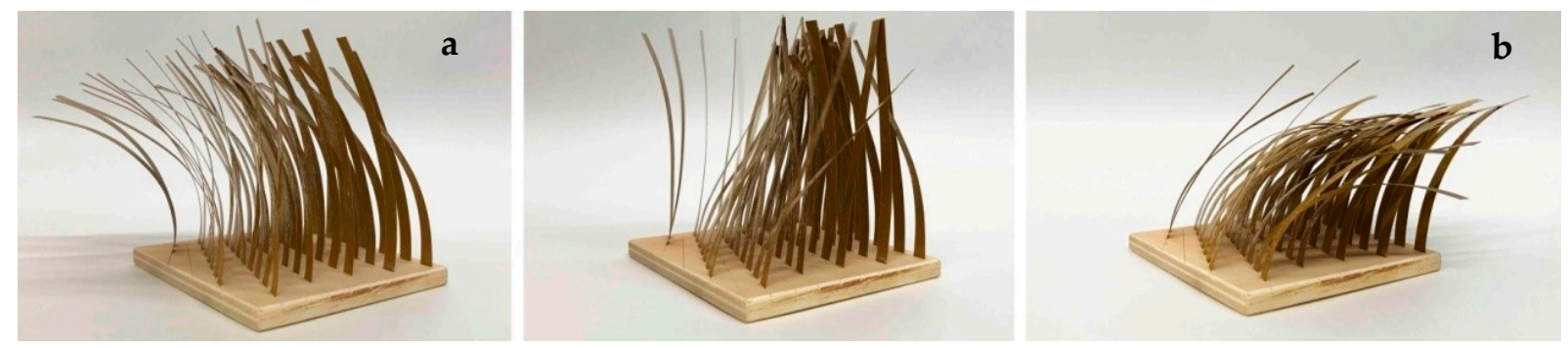

Figure 10. Recycled package paper and Kapton tape and their shape change influenced by temperature variations, $18^{\circ} \mathrm{C}$ (a) up to $50{ }^{\circ} \mathrm{C}(\mathbf{b}), 7$ row arrangement of the lamellae. 

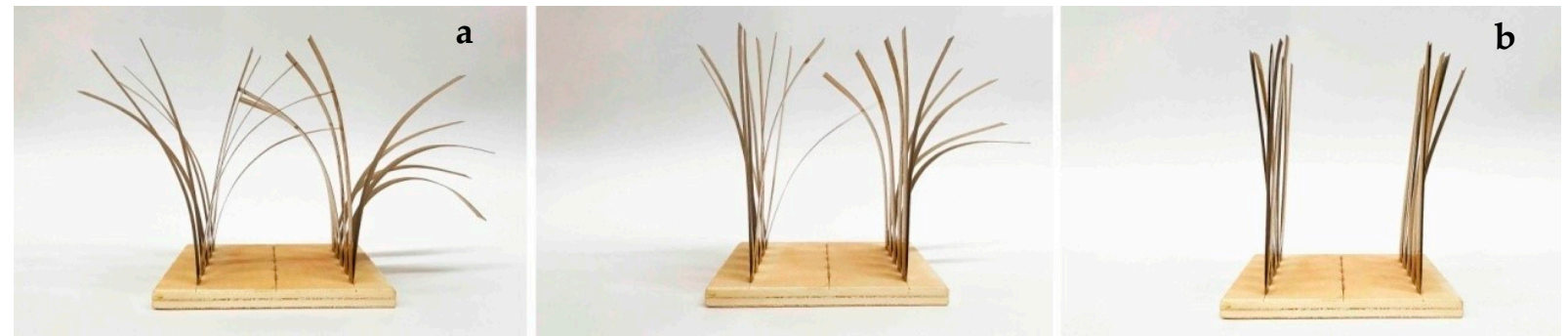

Figure 11. Recycled package paper and Kapton tape and their shape change influenced by temperature variations, $18{ }^{\circ} \mathrm{C}$ (a) up to $50{ }^{\circ} \mathrm{C}(\mathbf{b})$, front views, 2 parallel row arrangement of the lamellae.

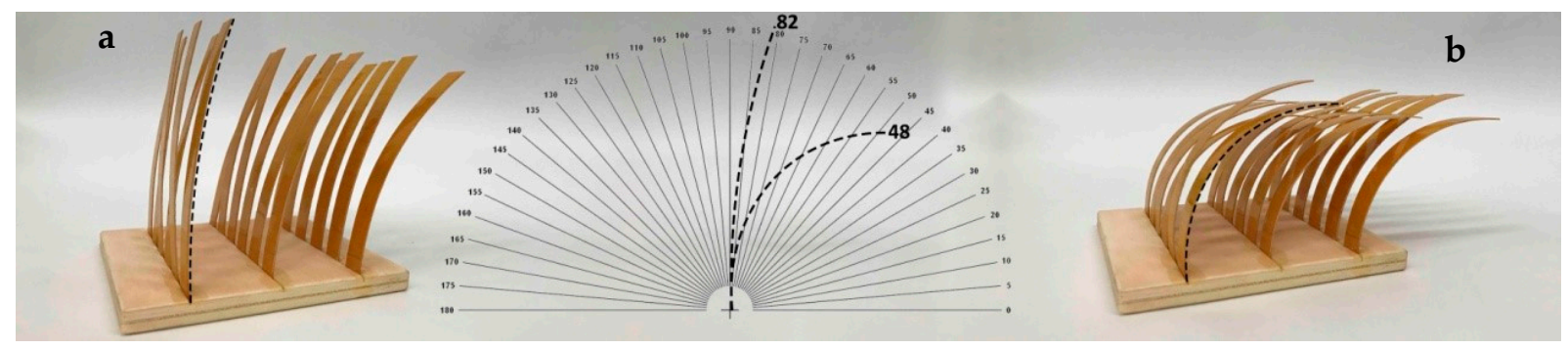

Figure 12. Tangential cut sycamore veneer and Kapton tape and their shape change influenced by tempera-ture variations, $18{ }^{\circ} \mathrm{C}(\mathbf{a})$ versus $50{ }^{\circ} \mathrm{C}(\mathbf{b})$ with resulted angle changes.

Acknowledging the physical impact temperature and humidity variations may actually have on local, natural, "non-smart" materials, we continued experimenting with diverse samples, in order to be able to draw relevant conclusions for the "Modgrew" installation and the possibility of changing its technological background into a smart, yet ecological one. All in all, the best outcomes were achieved by drawing paper with a $110 \mathrm{~g} / \mathrm{m}^{2}$ density and the following composition (based on the description of the producer: $75-80 \%$ cellulose, $13-18 \%$ filling material, $2 \%$ binding agent and optical bleacher, $5 \%$ water).
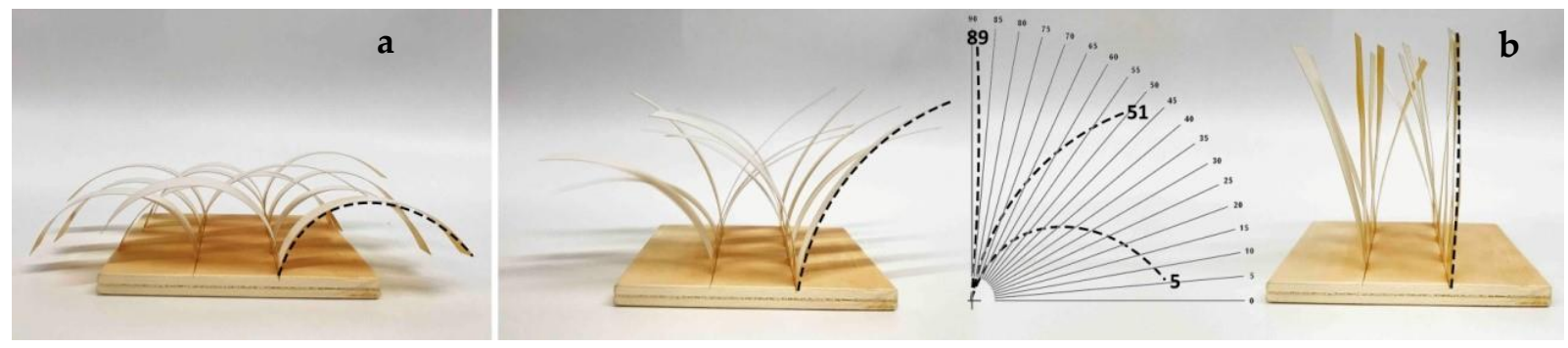

Figure 13. Drawing paper and Kapton tape and their shape change influenced by temperature variations, $18{ }^{\circ} \mathrm{C}$ (a) up to $50{ }^{\circ} \mathrm{C}(\mathbf{b})$ - conclusion: best sustainable prototype used for further study.
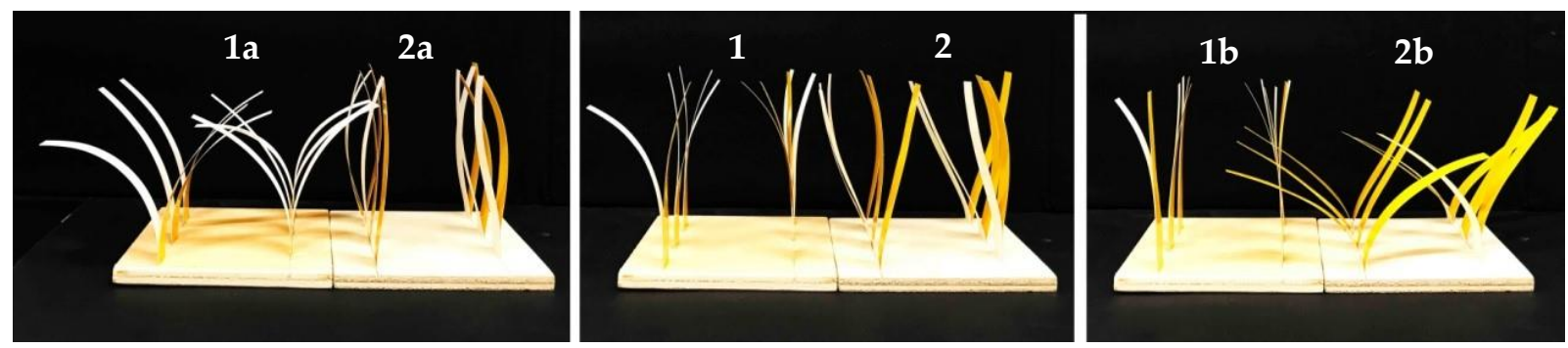

Figure 14. Drawing paper and Kapton tape-comparison between 2 different samples with tape on the exterior (1) and interior (2) and shape change influenced by temperature variations, $18^{\circ} \mathrm{C}(\mathbf{1 a}$ and 1b) up to $50^{\circ} \mathrm{C}$ (2a and $\left.\mathbf{2 b}\right)$. 

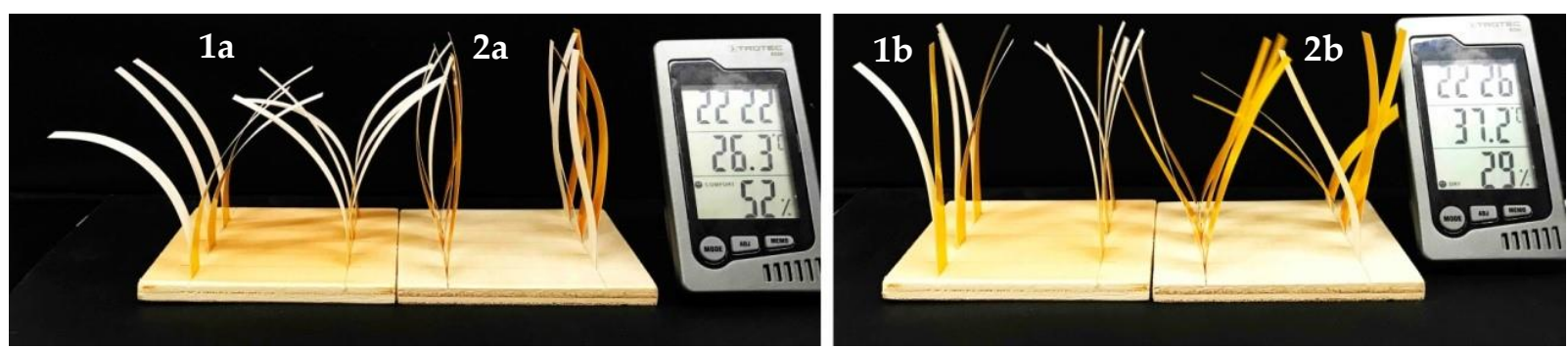

Figure 15. Drawing paper and Kapton tape-comparison between 2 different samples with tape on the exterior (1) and interior (2) and shape change influenced by temperature variations, $18^{\circ} \mathrm{C}(\mathbf{1} \mathbf{a}$ and $\mathbf{1 b})$ versus $50{ }^{\circ} \mathrm{C}(\mathbf{2} \mathbf{a}$ and $\mathbf{2 b})$ with thermometer.
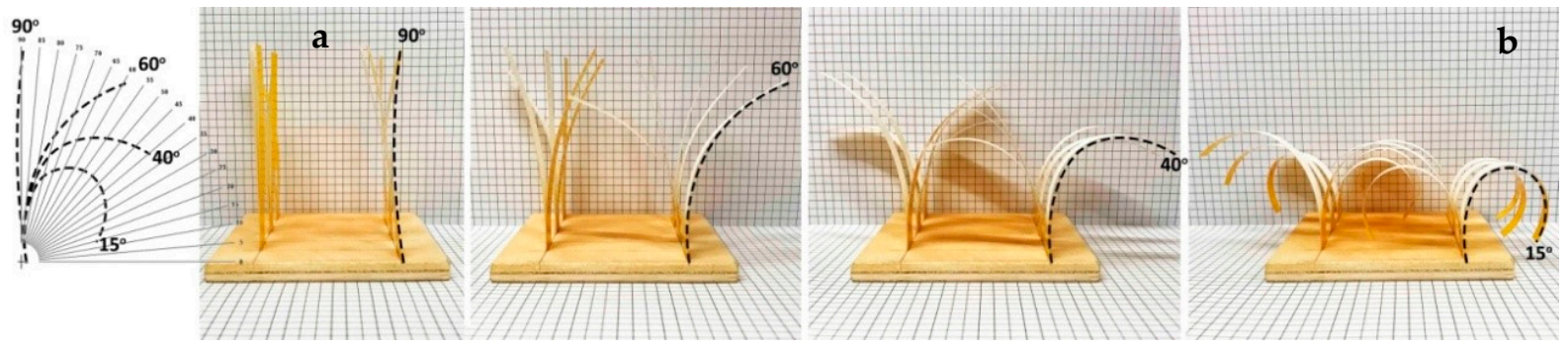

Figure 16. Final sample, drawing paper and Kapton tape on the exterior-their shape change influenced by temperature variations, $18{ }^{\circ} \mathrm{C}$ (a) up to $50^{\circ} \mathrm{C}(\mathbf{b})$.
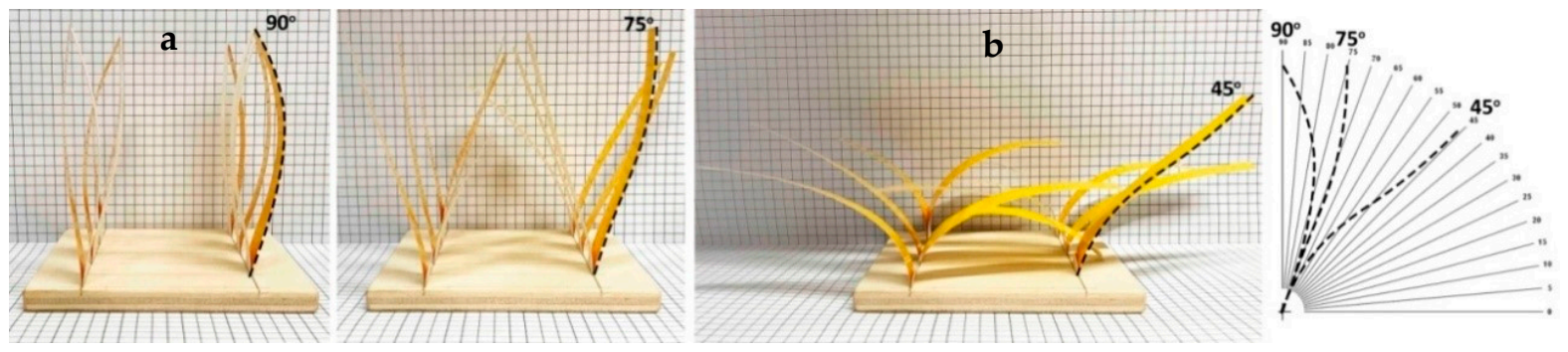

Figure 17. Final sample, drawing paper and Kapton tape on the interior-their shape change influenced by temperature variations, $18{ }^{\circ} \mathrm{C}$ (a) up to $50^{\circ} \mathrm{C}$ (b).

According to the low thermal inertia of the samples, the humidity was also an important part of the shape changes and transformations that appeared. Therefore, the actual process included changing the initial characteristics found in the laboratory $\left(23^{\circ} \mathrm{C}, 47 \%\right.$ humidity) to a second state generated by a lab oven $\left(50^{\circ} \mathrm{C}\right.$ for $\left.10 \mathrm{~min}\right)$, a third state generated by a lab refrigerator $\left(4^{\circ} \mathrm{C}\right.$ for $\left.10 \mathrm{~min}\right)$ and a fourth state made possible by returning to the lab initial conditions.
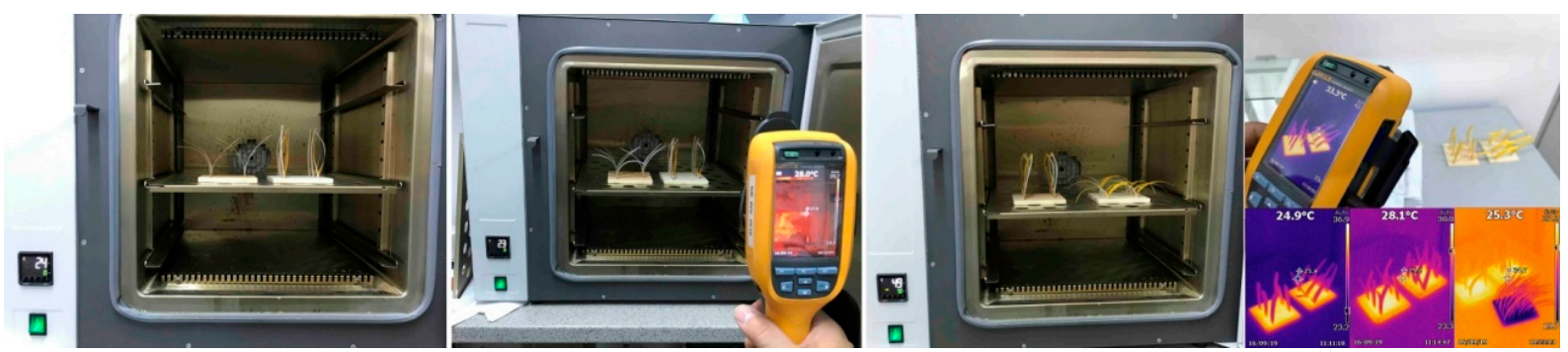

Figure 18. Lab oven and thermal imaging camera in successive experiment states.

In the issue, analogue interactive installations may also lead to the desired responsiveness to external stimuli and natural factors, such as temperature, air humidity or light, but 
how could these findings be linked to the initial "Modgrew" green plant-based concept and generate the desired movement through eco-friendly materials?

\subsection{Combining Modgrew Pyramidal Plant Container Module with Materials Prone to Change Their Shape Due to External Stimuli}

After the conclusions of the second part of the study, we started aiming to use the minimum amount of required sensors, technological apparatuses, and software in our project, in order to supplement certain actions in a natural, simple manner, by emphasizing the eco-friendly aspect of the endeavor. Therefore, new experiments were on their way to paving a new layer of facts and knowledge onto the "Modgrew" research.

The next concept intertwined the qualities previously identified in the pyramidal containers and with different angles and openings and in the natural abilities of some materials to actively respond to external factors, such as air humidity, temperature, or light. Adaptation was a key requirement for the functionality of the system, so the shape was obtained through a parametric definition shown in Figure 19.

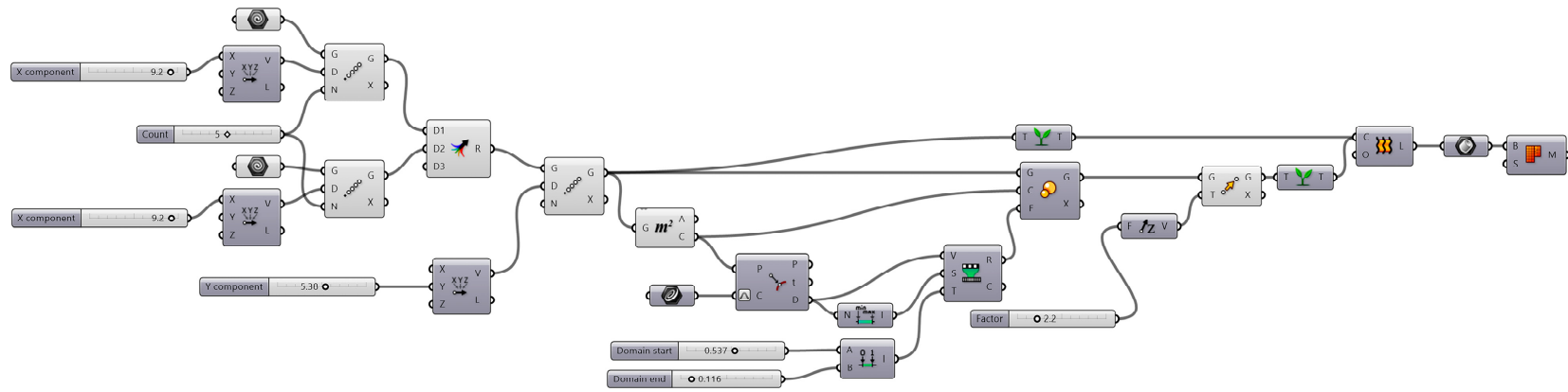

Figure 19. Pyramidal composition digital definition.

It also harnessed the knowledge previously acquired during the experimental parametric workshops. So, we generated a geometric definition that included pyramidal repetition, rhythm, successive opening, and scaling for the base as shown in Figure 20. Using a 3D printer, which we also had to calibrate ourselves as part of the academic workshop, we aimed to materialize the pyramidal containers as a base for the stimuli-sensitive lamellae as shown in Figures 21-30.

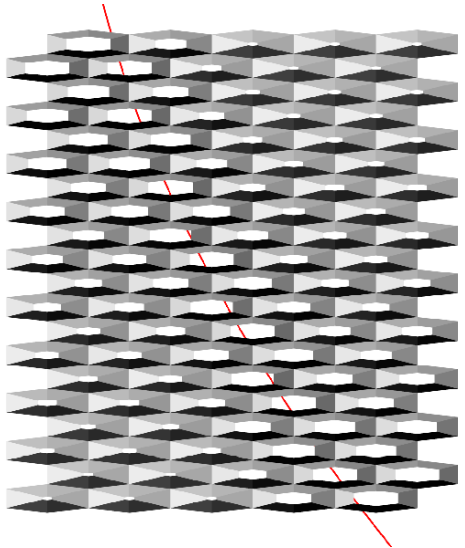

(a)

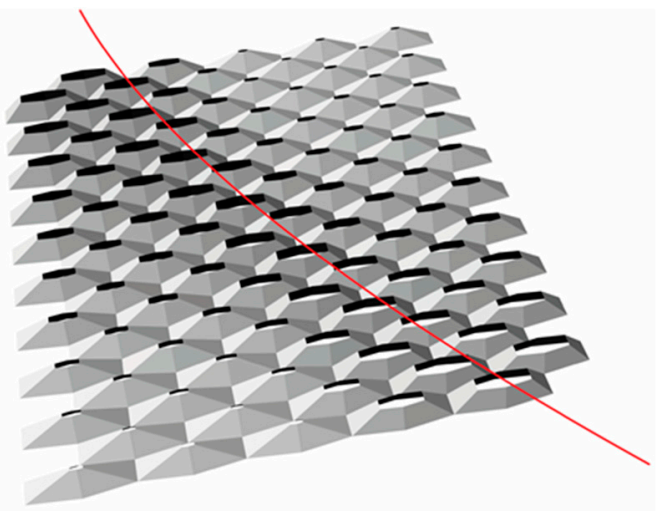

(b)

Figure 20. Proposed 3D parametric pyramidal geometry. (a) top view; and (b) perspective view of the adaptive surface resulting from the definition (the red line represent potential external stimuli).

The creative digital project was followed by a complex process dedicated to the materialization of the proposed parametric composition. It was demanding because of the scale of the chosen model, the lack of repetition in pyramidal modules and a new 
factor that entered the equation, the necessary 3D printer acquired through the research grant itself (GNaC2018 ARUT, no.1347/1 February 2019, financed by Politehnica University of Timisoara, Romania). Geometry files were divided into units, converted using 3D printer-friendly recognized software.
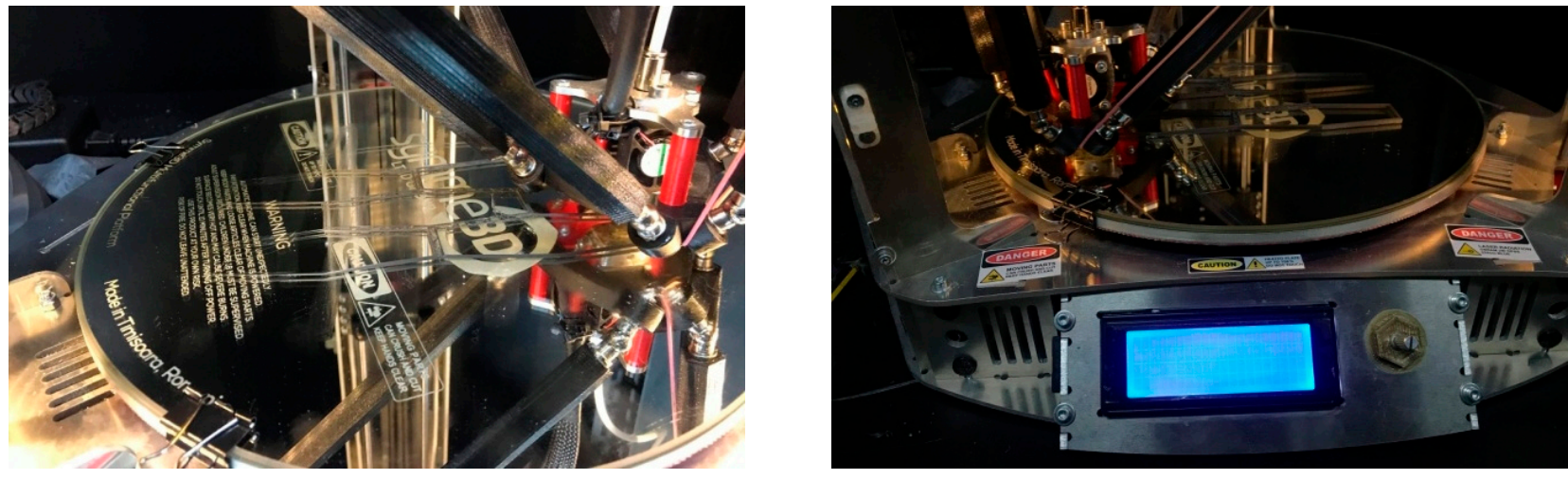

Figure 21. 3D printer settings and start of prototype printing.
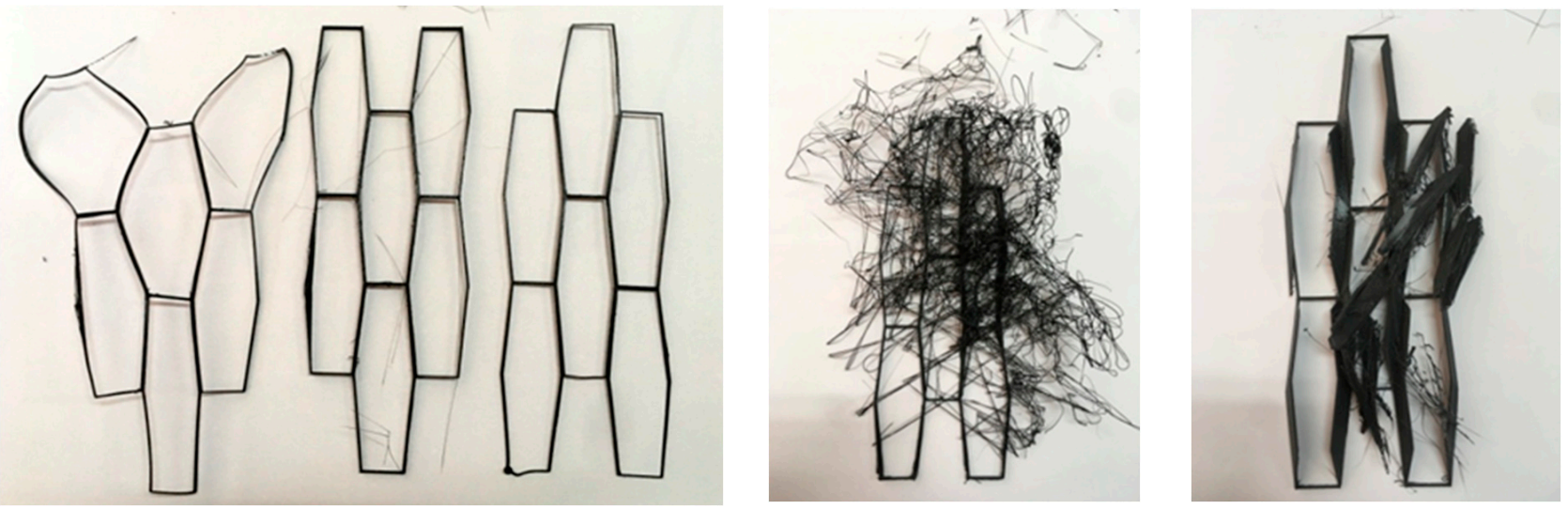

Figure 22. Pyramidal base failures due to inadequate 3D printing settings.
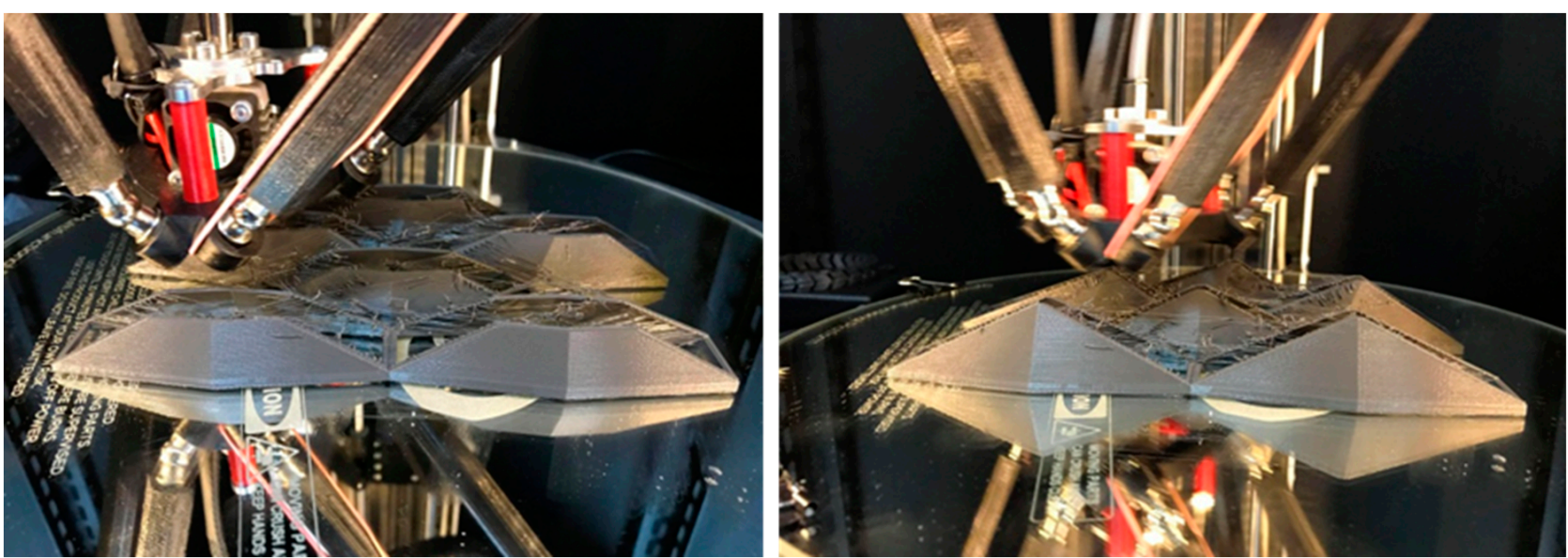

Figure 23. 3D successful printing process. 

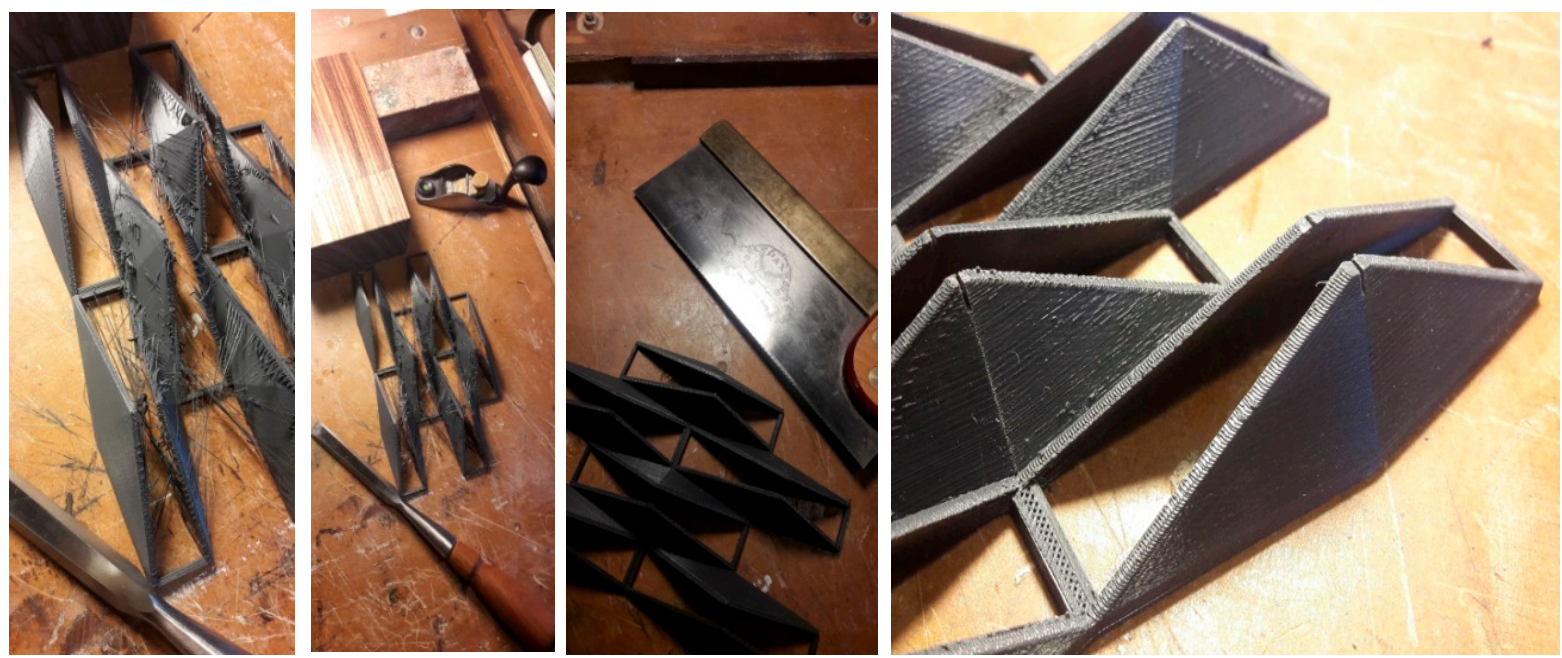

Figure 24. Manual technique of removing model printing and excess errors.
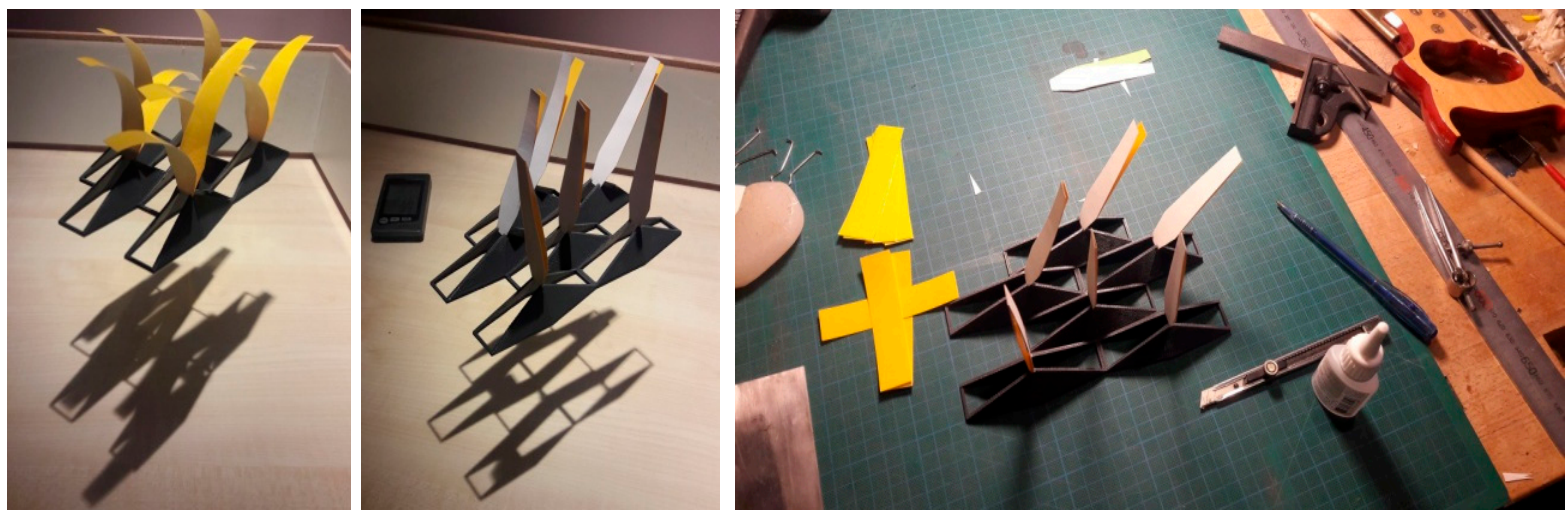

Figure 25. First successful samples of 3D printed modules with shape-changing lamellae.
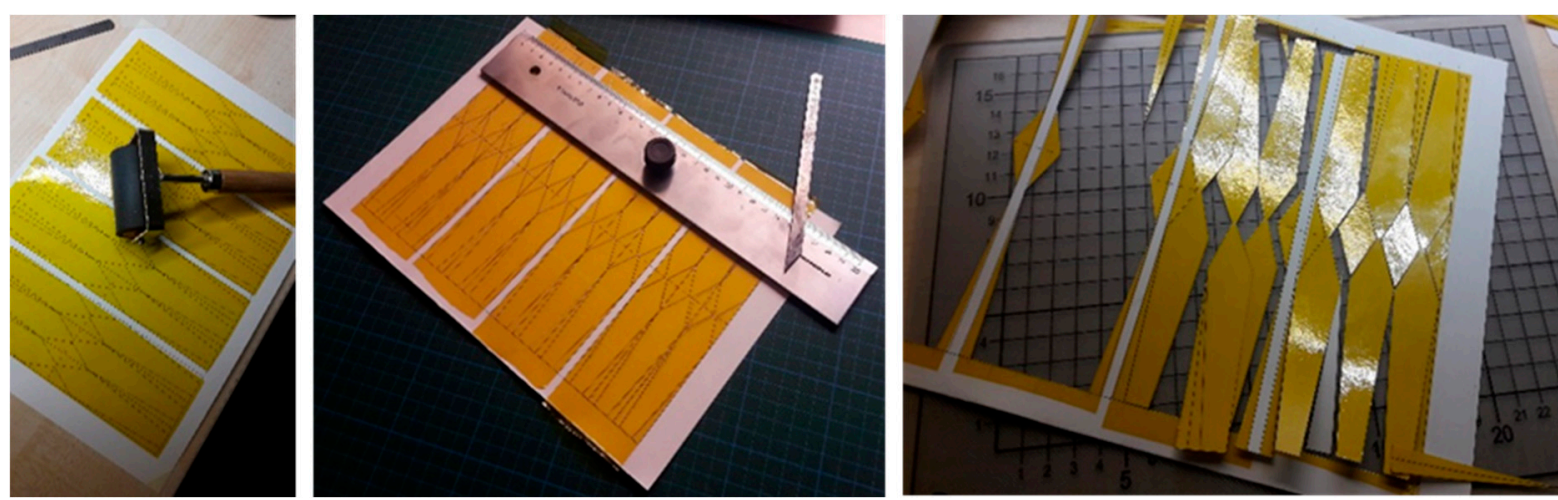

Figure 26. Printing, gluing, and cutting processes for the shape-changing lamella. 

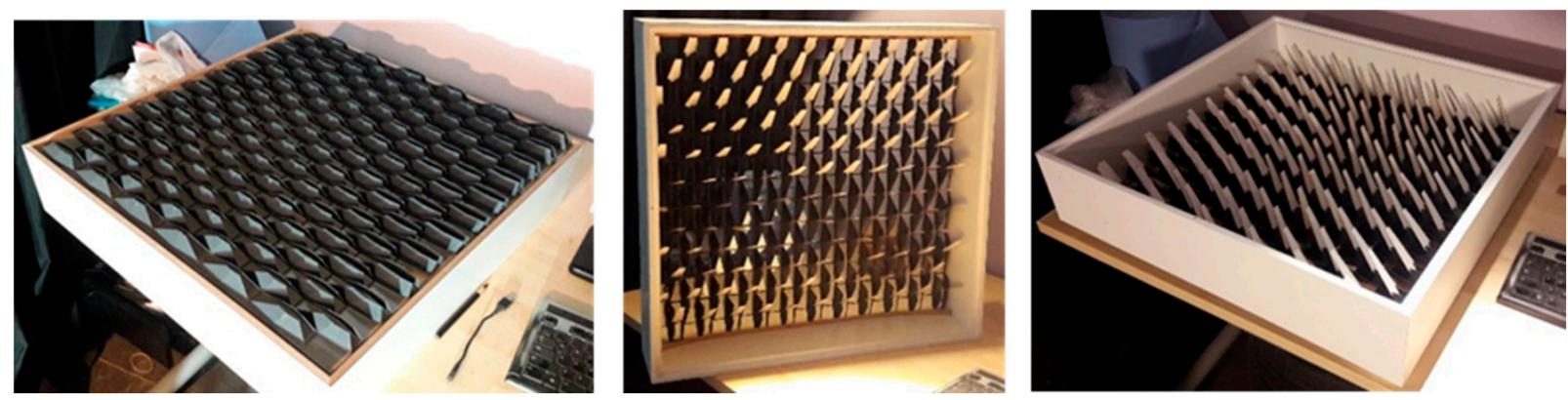

Figure 27. Assembled model consisting of the 3D-printed modules, lamellae, frame, and glass panel.
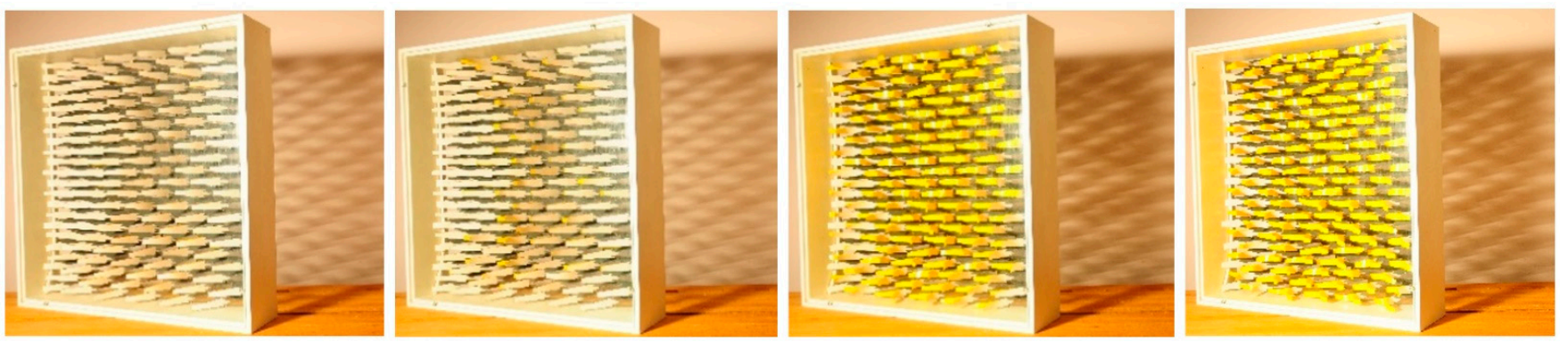

Figure 28. Assembled model and physical reaction and movement of the shape-changing lamellae, right view of the model.
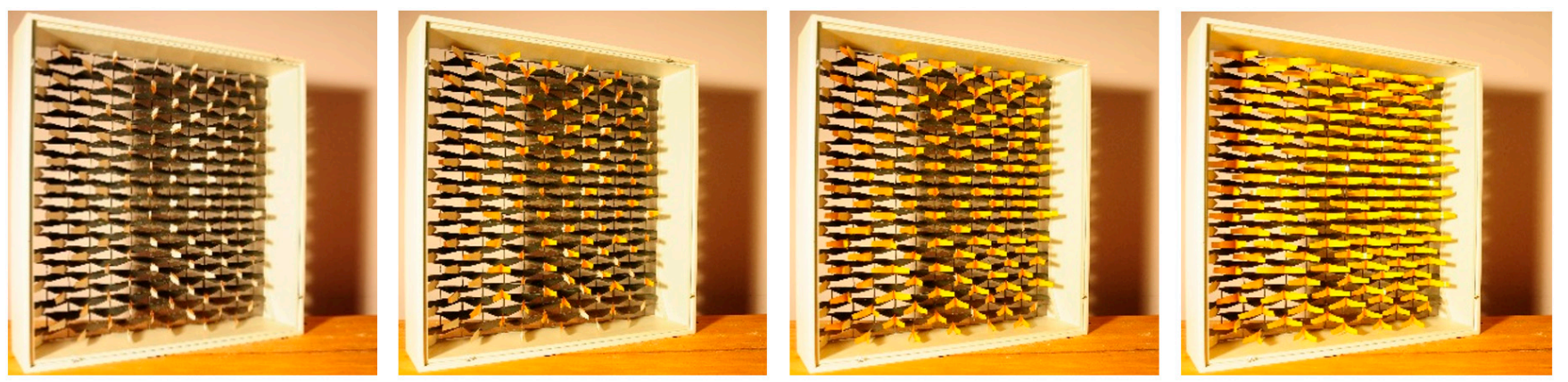

Figure 29. Assembled model and physical reaction and movement of the shape-changing lamellae, left view of the model.
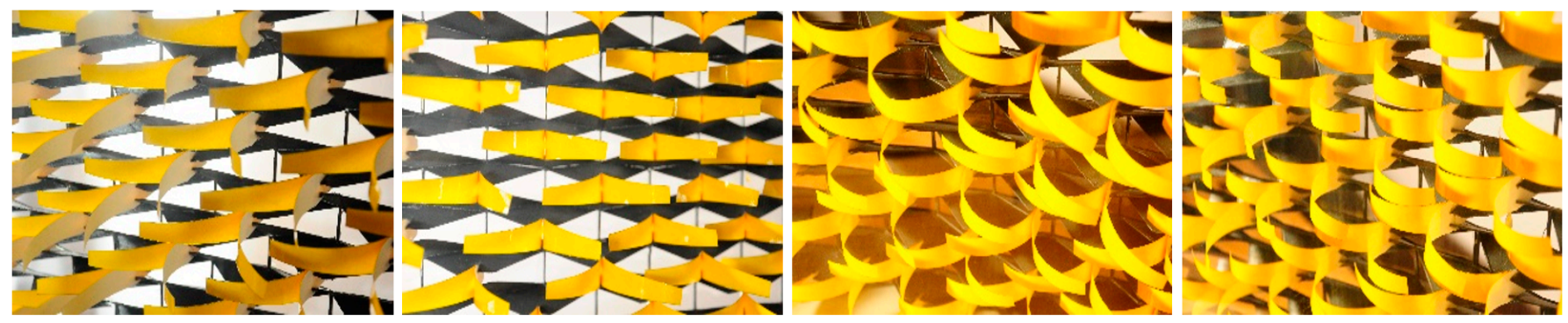

Figure 30. Details of the assembled model and its physical dynamic.

In conclusion, by the time of the last experiment, all previously acquired knowledge regarding parametric and digital design, modular projects and mechanisms, shape changing materials, 3D printing and modelling had been imperceptibly influencing the team progress. Even though many unknowns regarding the materials' actual behavior have generated a winding development and evolution of the physical materialization of the concept, the team's previous research, experience and enthusiasm have led to an innovative model meant to redefine interactive, eco-friendly, external factors' responsive, dynamic installations. 


\subsection{ModgrewModular, Green, Responsive and Interactive Final Installation}

Based on all previous experiments, the final installation was made from interactive modular systems that united all previous experiments accomplished by the research team into a new, living, dynamic, interactive structure, whose inspiration was taken from nature while using biomimicry as the main principle for its development [27]. The structure would respond to and would be influenced by external, natural stimuli. Thereby we emphasized the natural direction of the research by using simple materials and minimum required digitalization to activate the structure through sensors and actuators that would react to external environmental stimuli (humidity and light). Starting from an installation at the human scale level, we developed the concept into a larger scale interior or exterior panel meant to encourage the acceptance of an interactive, green wall that included the following functions: a growth media for various plants with a built-in irrigation system and light sensor-activated movement and, last but not least, a display area for information regarding the system and its position in space (be it in public transportation nodes or in interior public areas, such as university atriums).

The volumetric ensemble was based on parametric digital design (Figure 31) similar to the previous projects, while we experimented with diverse types of geometrical influence different lines, curves or volumes could have on the final result. Moreover, through simulations, we also studied the visual and aesthetic influence such an installation could have on interior and exterior spaces (Figure 32).

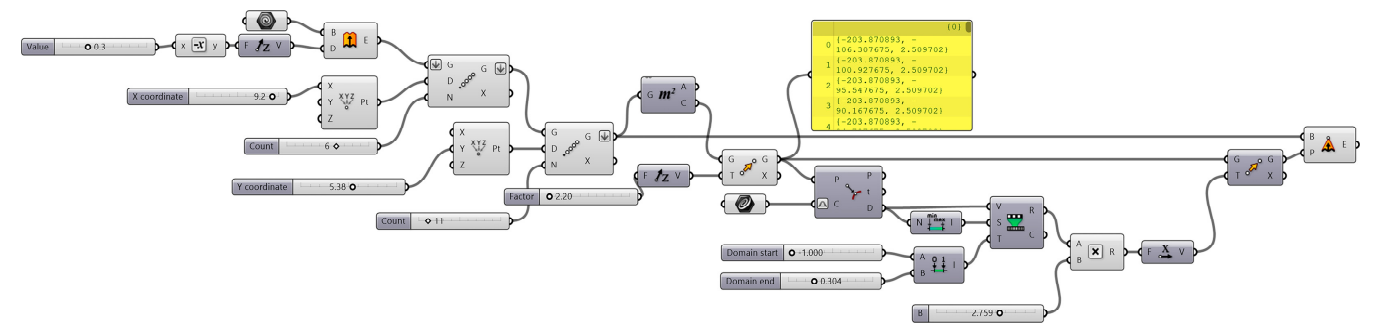

Figure 31. Digital parametric definition.

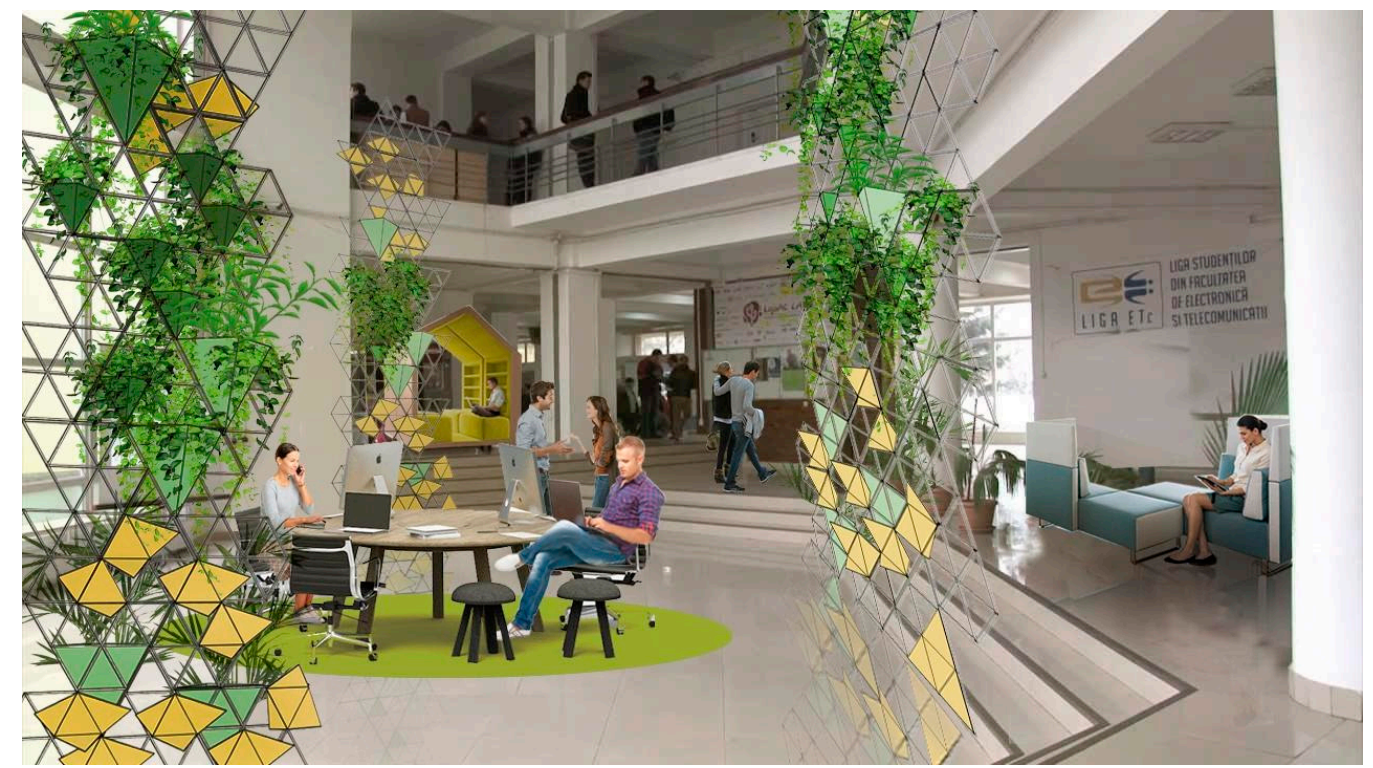

Figure 32. Conceptual simulation: volumetric vertical installations (for interior or exterior spaces).

The volumetric ensemble was thus developed into a modular system consisting of pyramid-based volumes designed as complex planter for a hydroponic green wall. The installation would move and rotate its modules defined by the pyramids according to environmental factors (Figure 33) captured by both natural materials responsive to external 
stimuli and the supplemented sensors, and also be interactive in order for passers-by to be able to play with its openness and responsiveness from all points of view as shown in Figure 34.

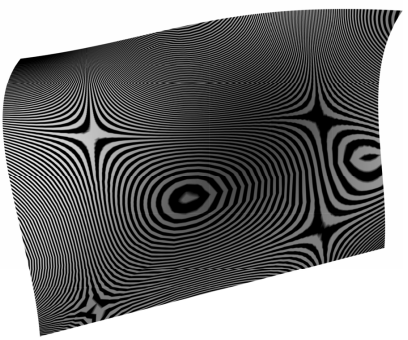

(a)

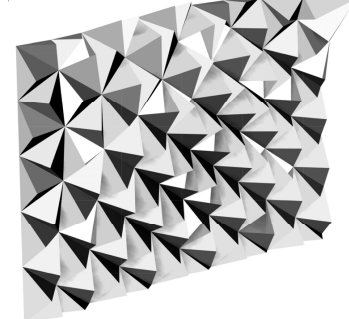

(b)
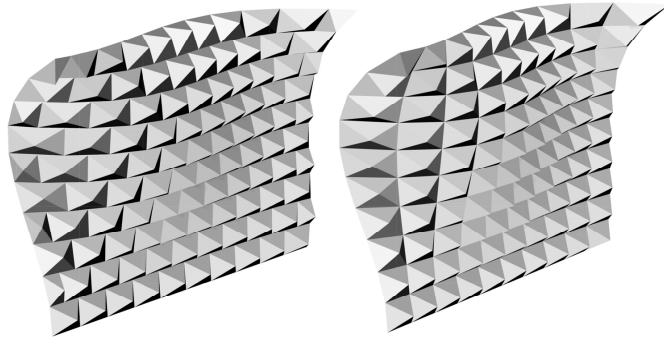

(c)

Figure 33. (a) Volumetrically influential zebra-striped surface; (b) Triangular pyramid panel generated by the increments of the zebra-striped surface; and (c) Rectangular pyramid panel generated by the increments of the zebra-striped surface.

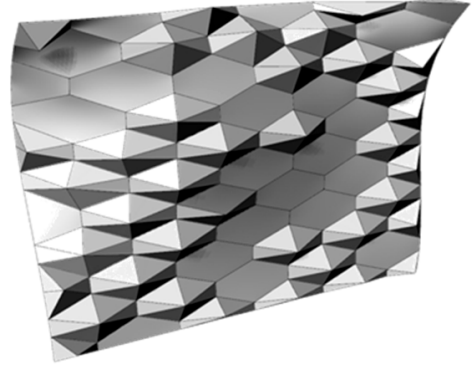

(a)

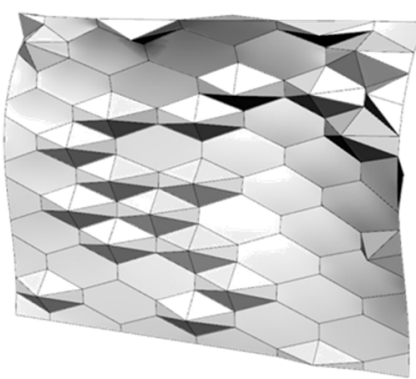

(b)

Figure 34. (a) Installation frontal pyramidal array; (b) Installation posterior pyramidal array.

The modular pyramid panel was detailed and, in our search for the optimal functional and aesthetic version, the project went through a multitude of experiments and changes. Figure 35 presents a series of iterations used to test the definition for a simple, 2D module. Once the desired model was achieved the three-dimensional module was inserted, as seen in Figure 36.

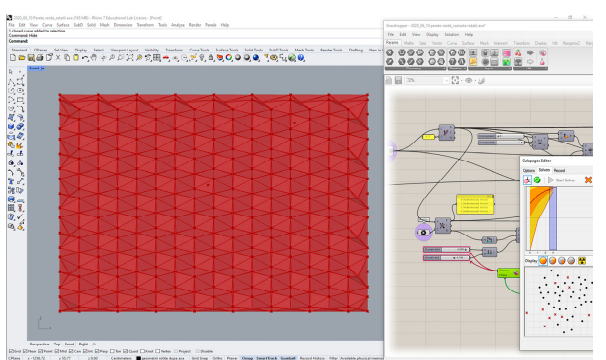

(a)

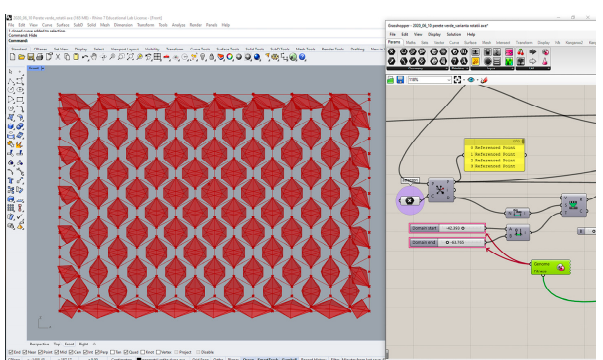

(b)

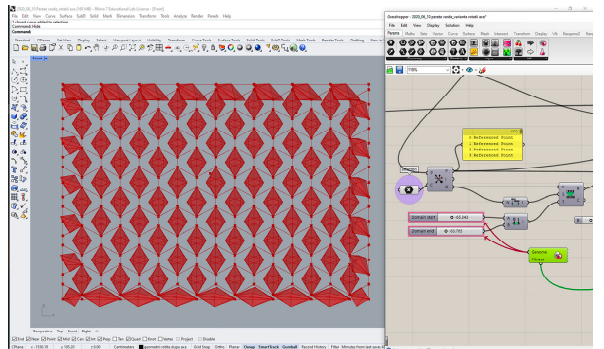

(c)

Figure 35. (a-c) Installation array of identical flat-based pyramids. 


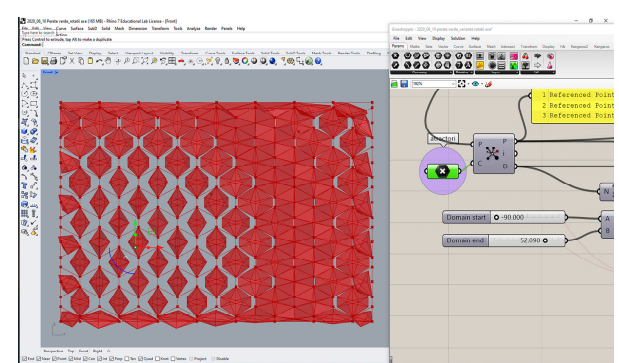

(a)

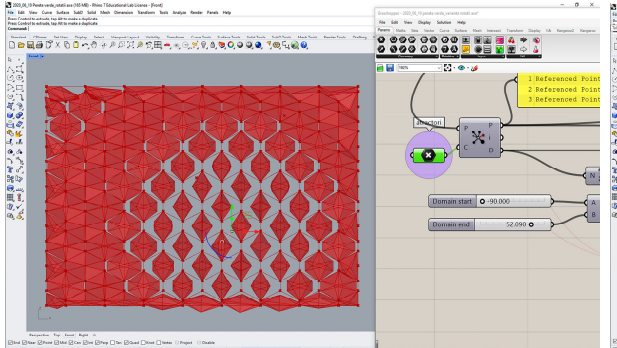

(b)

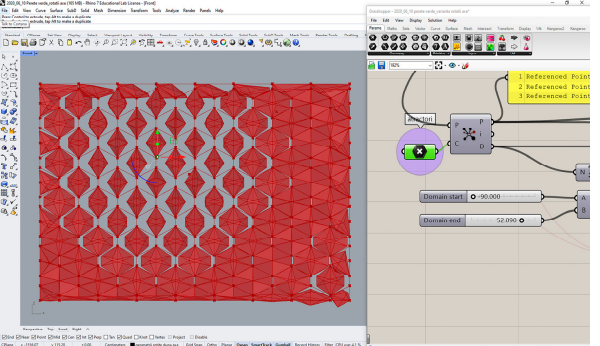

(c)

Figure 36. (a-c) Installation array of identical pyramids with three dimensional bases.

The next phase was adding a structural grid to support the whole system and voids allowing space for plants (Figure 37). Eventually, the tests and trials led us to the model that encompassed all sought design features sufficient space for small plants, three dimensional and rhythmic design for visual architectural impact, representation surface area for displays of information, module array for optimal movement and rotation generated by the influence of external stimuli. To provide better access to natural light inside the module and simultaneously reduce material consumption, the final prototype shows a skeletal structure at the top as shown in Figure 38.

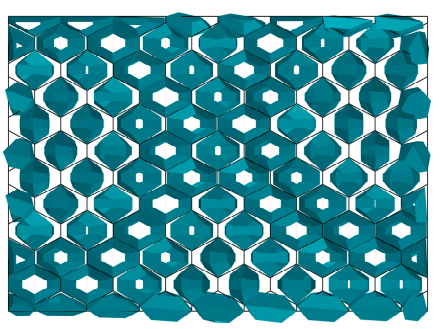

(a)

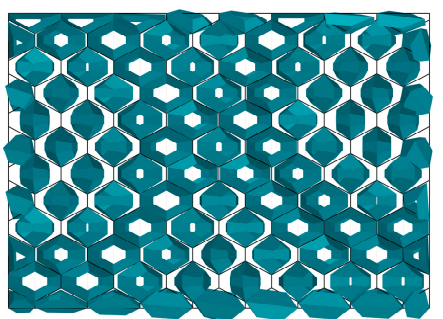

(b)

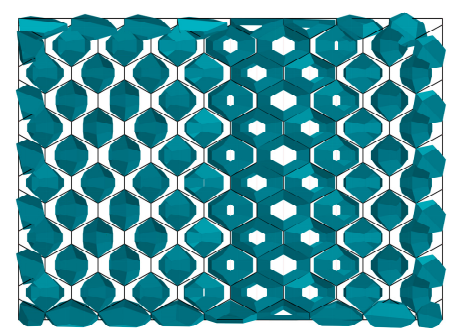

(c)

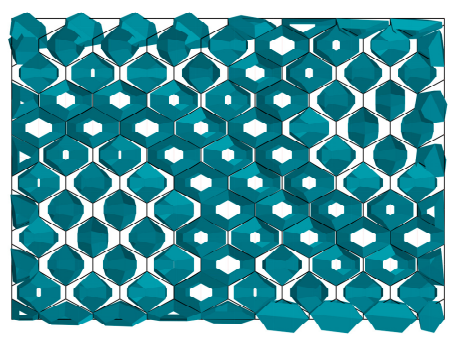

(d)

Figure 37. (a-d) Installation array of identical perforated pyramids.

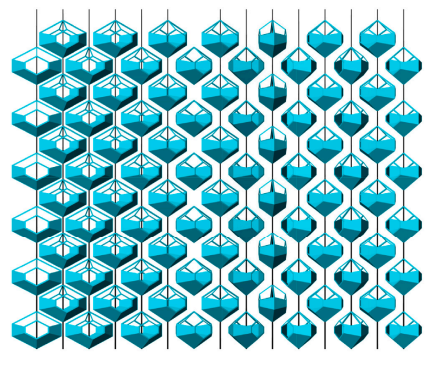

(a)

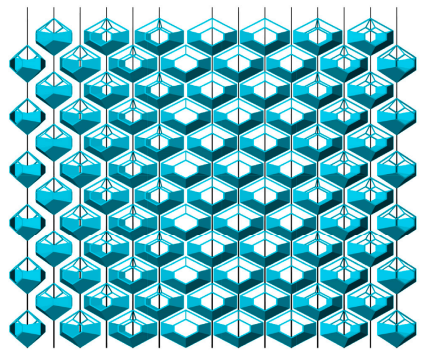

(b)

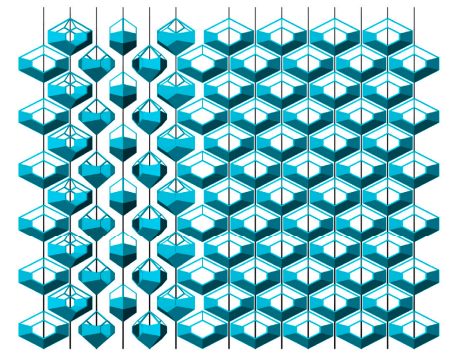

(c)

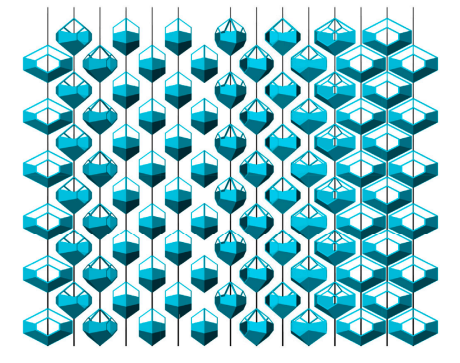

(d)

Figure 38. (a-d) Installation array of identical perforated pyramids with planter areas.

The final prototype (Figure 39) could be analyzed both at a macro scale (that of the entire system) and at a micro scale (that of the module). It involved the principle of hydroponic green walls with an imbedded circular irrigation system, which we took into consideration as inspiration for the functional basis, due to the sustainable advantages and high degree of autonomy of such ensembles. By excluding soil-based substrates, we avoided soil-based diseases and clogging issues, also optimizing planter space and achieving faster production results [28]. 

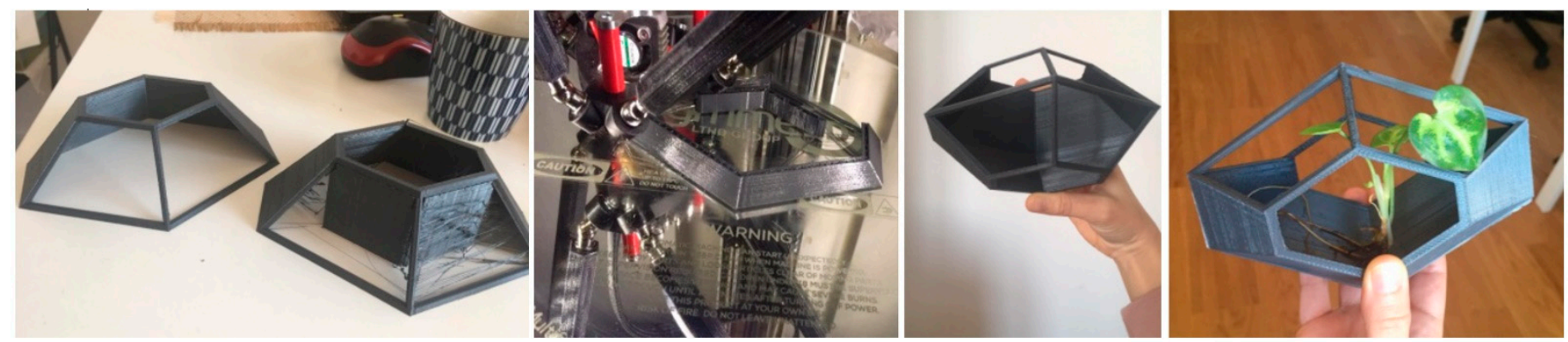

Figure 39. First successful samples of 3D printed modules with planter areas.

Plant species suitable for hydroponic mediums can be as diverse as for any planting system, from eatable vegetables and small fruit to tropical plants and herbs. The sole difference is the light requirement for various species. Hence the light sensor was added, which, depending on the intake of natural light, would activate a revolution movement of the support axis. Another variation would be positioning the system in interior spaces where upper-plan cells would not receive enough light, thus involving an additional LED grow light component, aspect on which the present paper will not insist. More precisely, the module is made up of two different zones. Whereas the main external focus resides on the green panel with modular growing chambers, the functional area enables the entire mechanism to function accordingly.

A complete image of the final prototype can be seen in Figures 40-43 and will be further described. Firstly, the individual modules are aligned on a vertical axis that supports their structure, which is attached in an articulated manner to the rotation axis that represents the actuator. The surface that includes the green modules is determined by the dimensions of $1968 \mathrm{~mm}$ and $2496 \mathrm{~mm}$. In addition to the planted area, the informational display also generates visual interest through its courageous shape, informational content, important position on the structure and its $1968 \mathrm{~mm}$ height. Secondly, the functional mechanism is inapparent, yet indispensable. It is based on two main premises: supplying the plants with water and light. The base of the structure includes a $3146 \mathrm{~mm}$ long and $300 \mathrm{~mm}$ high water reservoir, whereas the vertical pillar includes the necessary submersible pump with delivery tubes. On the upper area with the same length of $3146 \mathrm{~mm}$ and the same height of $300 \mathrm{~mm}$, the inserted light sensor (photoresistor) is programmed to identify the existing lighting levels. The entire mechanism can be fitted into a maximum width of $298 \mathrm{~mm}$.

The electrical and automation part (designed for $230 \mathrm{~V} \mathrm{AC}$ ) consists in:

- 4 Loom Solar 50 watt off grid solar systems, located on the top, providing $200 \mathrm{~W}$ of power, on $230 \mathrm{~V} \mathrm{AC}$, in parallel connection. The width of the system on the top will increase from $298 \mathrm{~mm}$ to $430 \mathrm{~mm}$, due to the solar panels.

- $\quad$ One Waldbeck Nemesis T90 (90 W, fresh water, submersible pump, up to $4 \mathrm{~m}$ height);

- $\quad$ Sprinklers and adapted hoses for at least 4 irrigation points on the top of the panel;

- 15 Honeywell N05230-2POS, 2 W NON-SPRING Return Direct-Coupled Damper Actuators for position control, on each of the axes;

- $\quad$ One Avidsen 103,202/230 V Twilight Sensor for light control;

- $\quad$ One Panasonic AFPX-C30R PLC with 16 inputs and 14 relay outputs connected with an AFPX-E16R Extension module with 8 relay inputs/outputs. This will directly control the whole automation on $230 \mathrm{~V} \mathrm{AC}$;

- $\quad$ One Blackt Electrotech: 230 Volts Float Switch Sensor for Water Level Controller. 


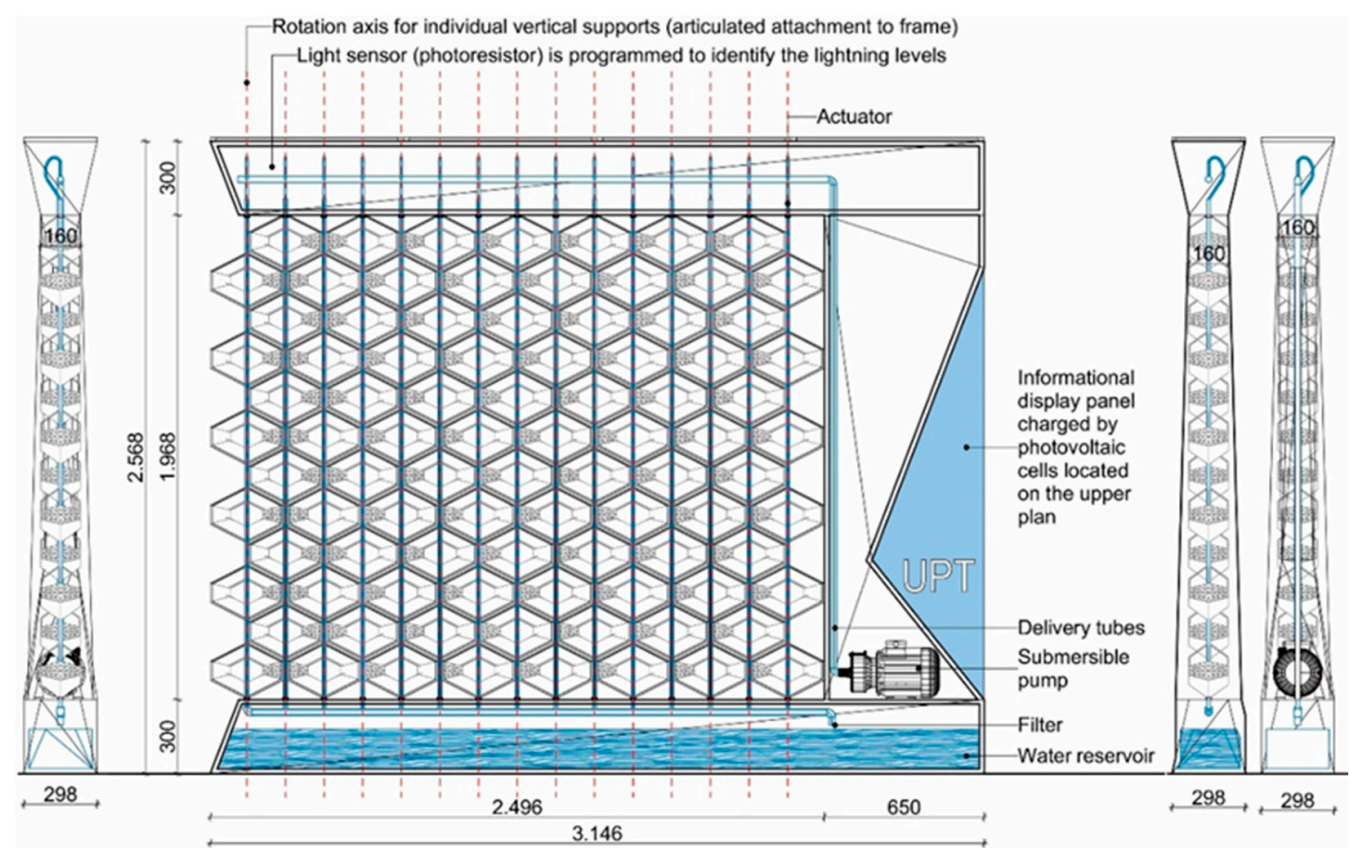

Figure 40. Final prototype technical drawings.

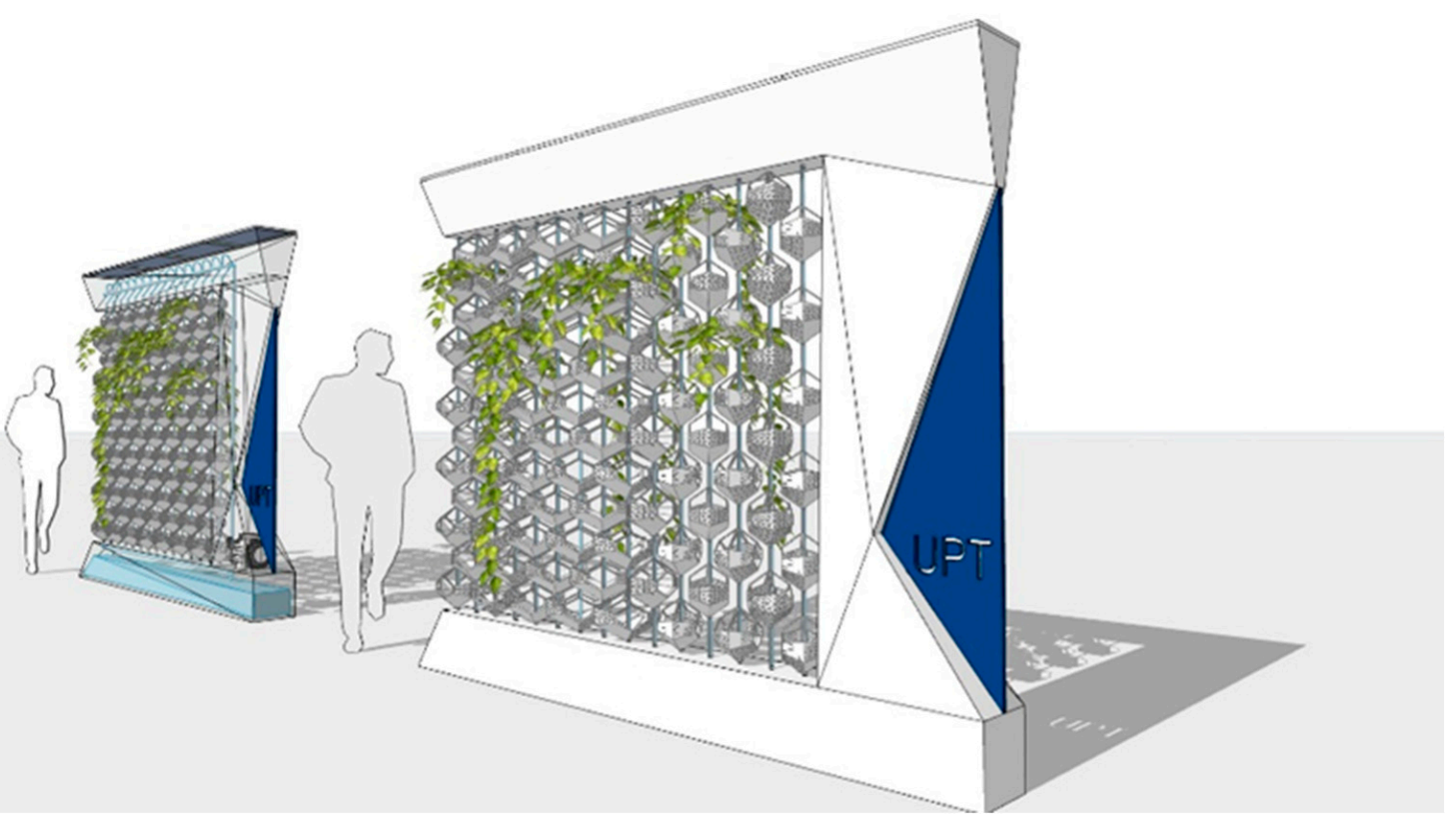

Figure 41. Final prototype technical drawings-perspective views, initial position of the modules and rotated position. 


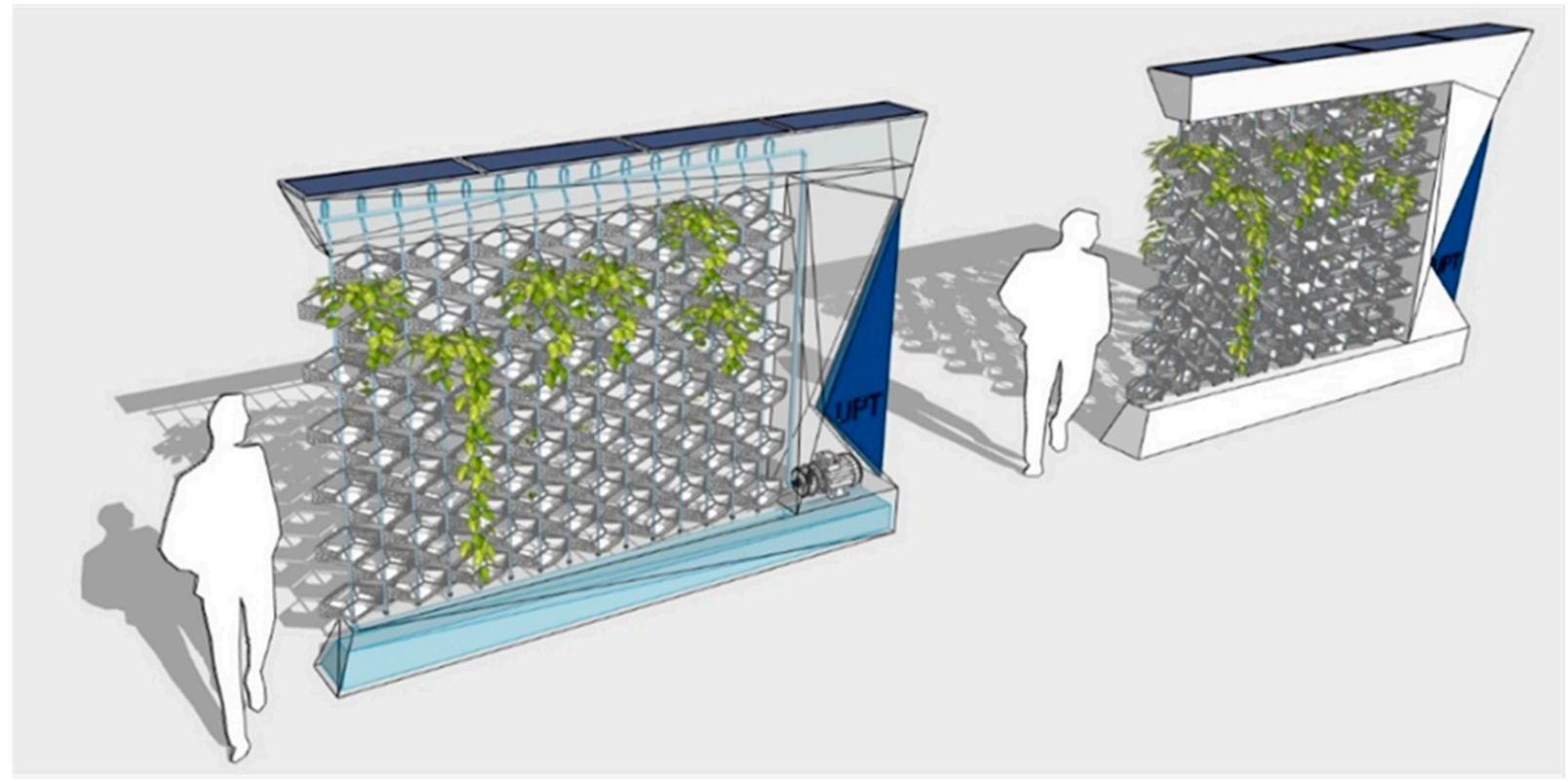

Figure 42. Final prototype technical drawings-perspective views, initial position of the modules and rotated position, including aerial views of the photovoltaic cells.

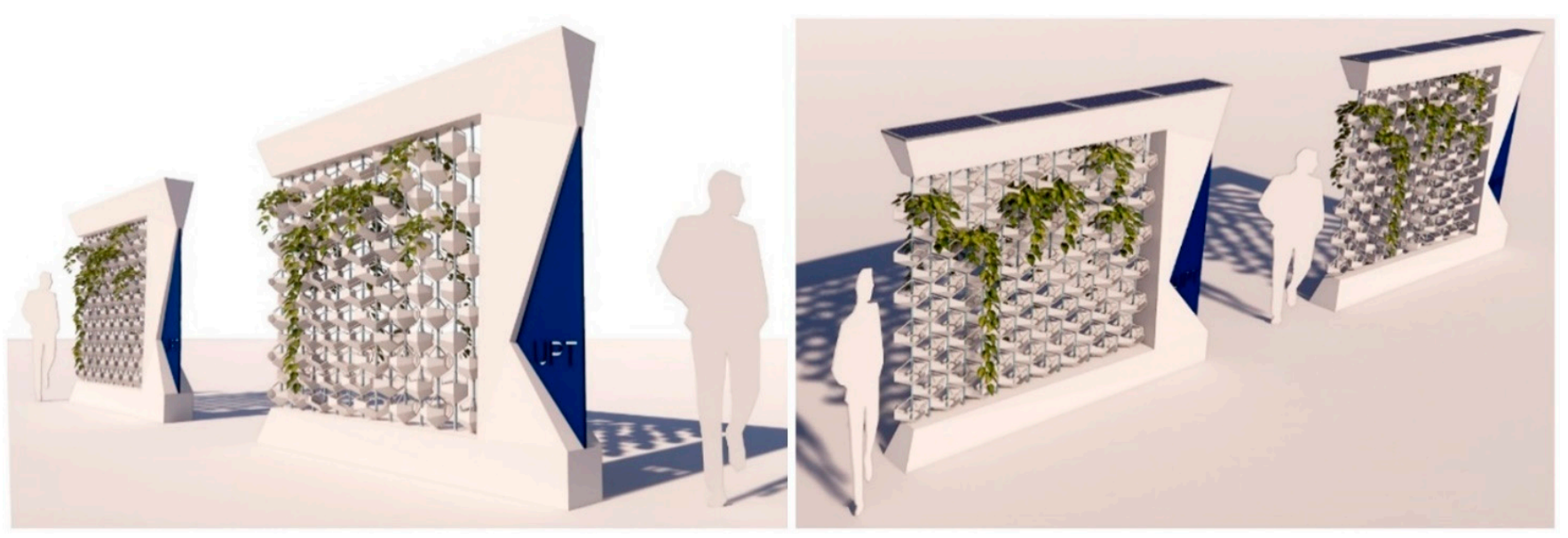

Figure 43. Final render-perspective views, initial position of the modules and rotated position as seen at a human scale.

A brief description of the whole Modgrew concept will be synthesized in Figure 44. Their materialization involved the realization of semi-functional prototypes at different scales 1: 10 or 1: 1 . 


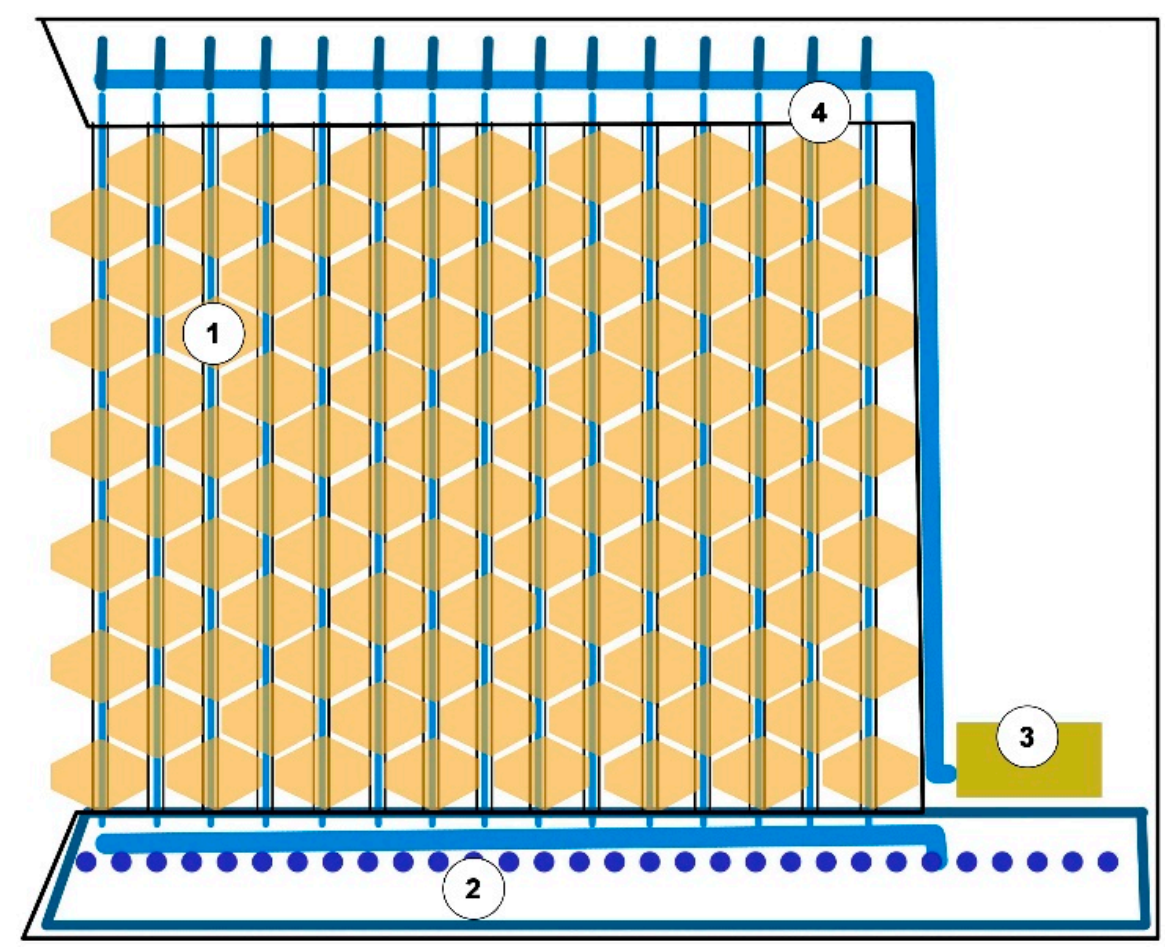

(A) Base system components

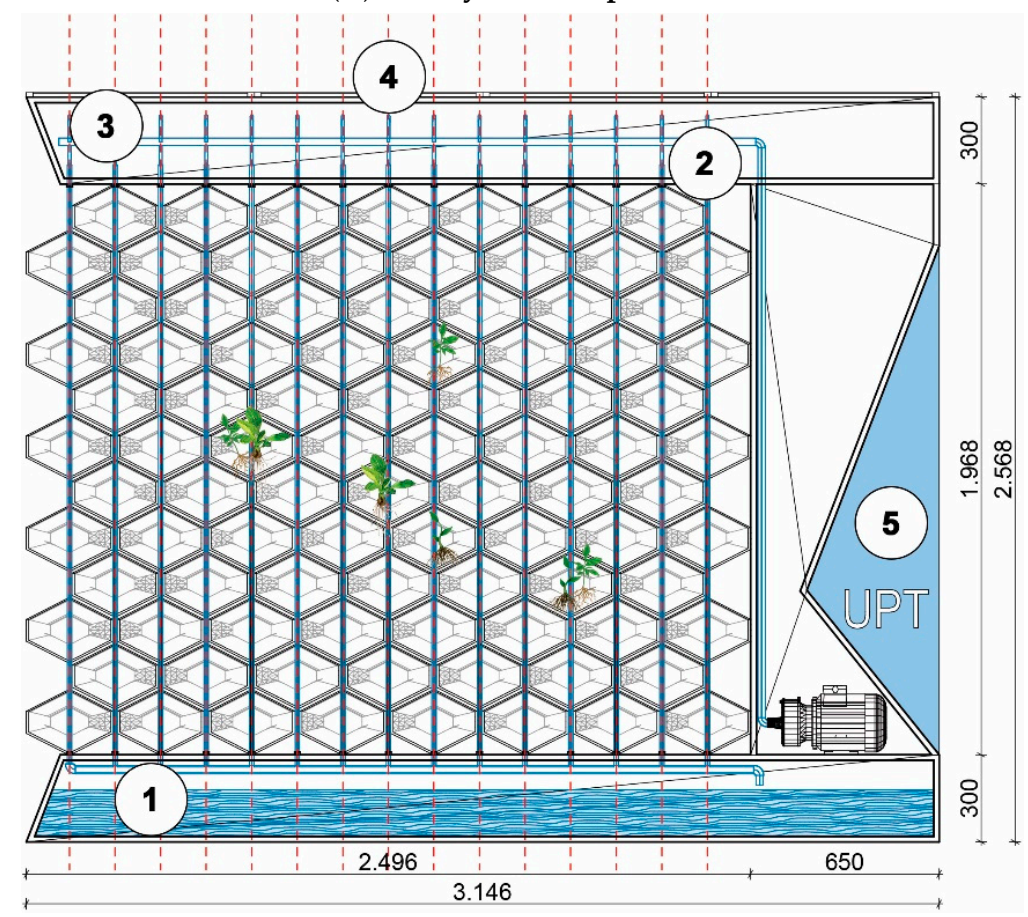

Figure 44. Cont. 


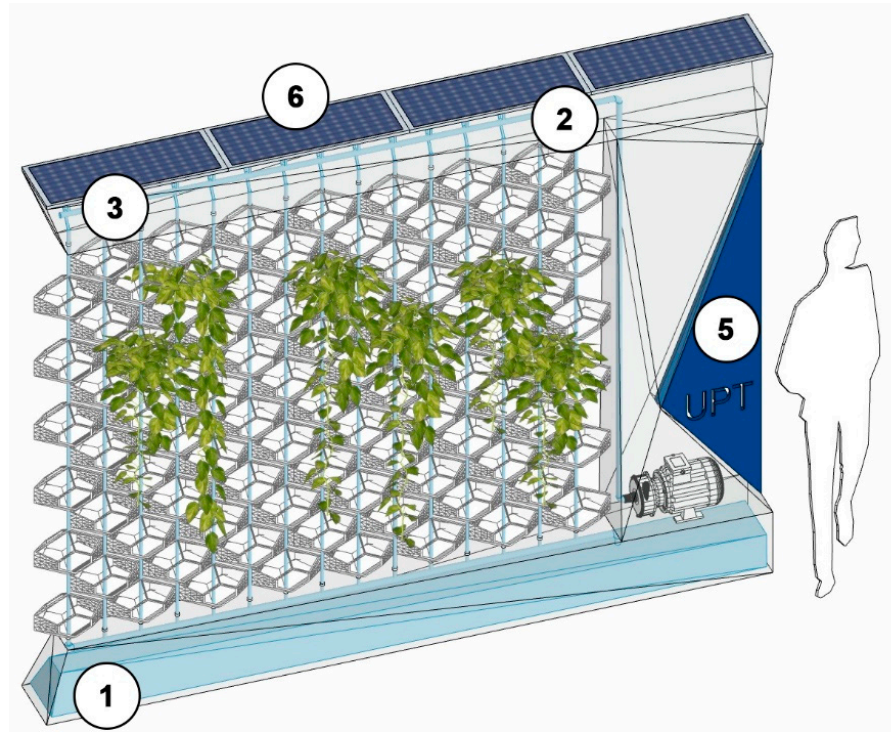

(B) MODGREW main automation features

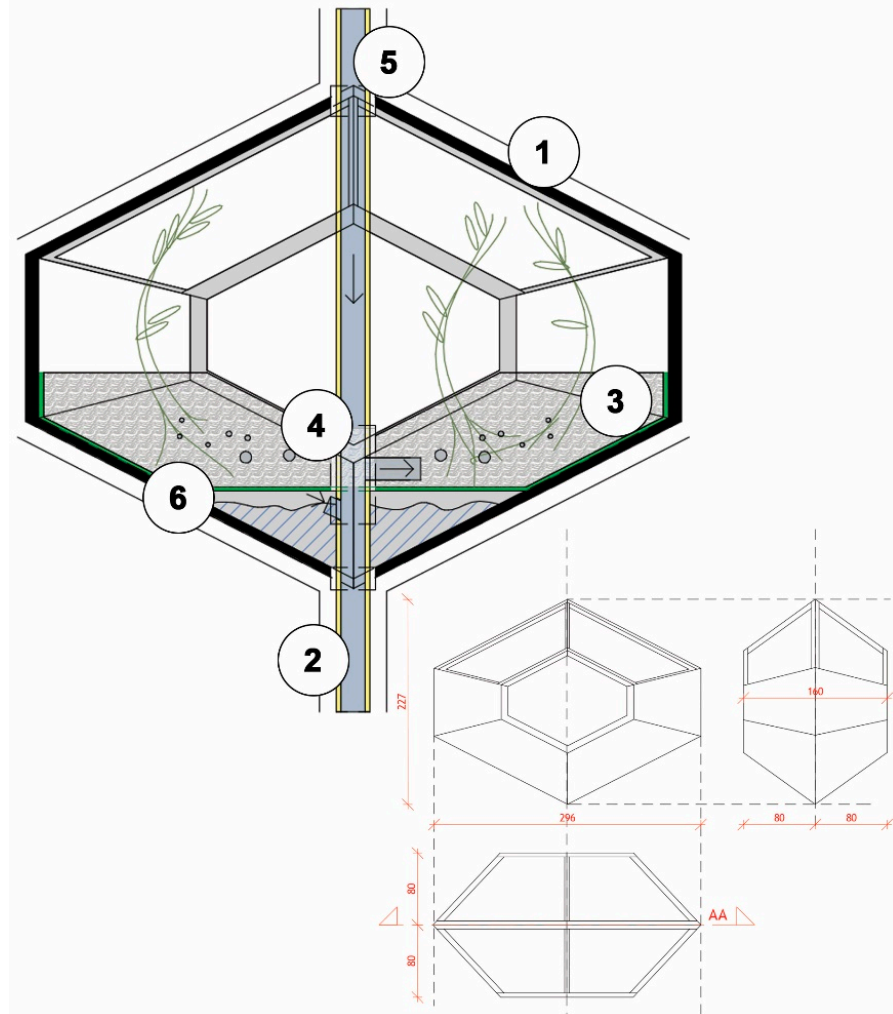

(C) MODGREW module components

Figure 44. Main features of the Modgrew system. (A) Growing chambers-base of each module (1), Water reservoir (2), Submersible pump (3), Delivery tubes-primary and secondary (4); (B) “C" shaped frame integrates the water reservoir, delivery tubes and other equipment (1), PLC based automation Irrigation system, which allows optimal watering of the plants (2), Light sensor placed to detect the exterior lighting levels (3), 15 rotation axes, one for each individual vertical support, articulated on base (4), Informational display panel for all pieces of equipment, connected to PLC, having a dedicated software application (5), and 4 Photovoltaic $200 \mathrm{~W}$ panels, located on the upper plan that power the whole assembly (6); (C) Complex geometry with full base and skeletal upper part (1), Circular section delivery tubes (flexible) + circular section support tube (metallic, rigid) (2), Growing chamber with porous growing substrate or root support adapted to plant species (3), Water alimentation and re-tention and overflow system (4), Elastic gasket (5), and Debris filtration layer (6). 


\section{Discussion}

The main research question of this study is related to advanced, intelligent, and environmentally integrated solutions applied in the field of both energy efficiency increase and architectural impact, based on new sustainable building elements. The adaptive design process was an integral part of this research, aimed towards obtaining functional module shapes that respond to both structural and aesthetic demands, as well as testing multiple flexible materials. As a result, the final prototypes represent strategies for sustainable building aspects through natural, passive solutions combined with technical elements.

This article starts from a case study, but, in the field of architecture and civil engineering, it presents some new energy efficient solutions, based on the shading effects of some new materials, as well as some new studies for implementing advanced green modular structures in our everyday urban environment, based on previous research, in a specific scientific manner.

It appeared as a continuation of previous projects of the team members, having as main objective the proposal of new technical solutions, scientifically argued, dedicated to intelligent measures to increase the energy efficiency of buildings, through active shading solutions, new materials, new architectural elements or by integrating plant elements in the structure of intelligent walls.

The main research question of this study is related to advanced, intelligent, and environmentally integrated solutions applied in the field of both energy efficiency increase and architectural impact, based on new sustainable building elements. This paper presents, in fact, a pilot project, and a dedicated set-up, which combines new architectural/biometrical elements with plants and green areas.

In other previous studies, the smartness of low-tech design was not directly addressed, or the focus was not on it but rather on acquiring a good answer but without taking into account costs or behavior over time.

Inspired by nature, and how plants and simple materials react to external light, temperature and humidity, the proposed interactive structure acquired an exterior shell or skin as part of the modular installation, in order to optimize environmental and human interaction with minimal technical solutions.

Many existing sustainable building solutions integrate a broad range of high energyconsuming components, contradicting the main purpose of bringing architecture closer to nature. The presented study argues that natural resources may complement technical solutions, by using natural principles and shapes to obtain comparable results for shading and green walls. The research brings new insights into the design process, through multiple academic experimentation methods that lead to the creation of systems that better interact with the surrounding environment and require less energy.

Study limitations primarily refer to the potential irregularities of external natural stimuli that may impact the prototype, such as temperature, humidity, light and plants. Secondly, the printing material may undergo slight deformations in time, when exposed to excessive heat, thus demanding further studies regarding material optimization on both prototype scale and real-life scale.

Future directions aim towards the development of the proposed system, regarding monitorization in time and practice, while also testing different module materials that would assure stability and resilience to external factors. Due to the conceptual character of such a prototype, it has not yet been tested on a large scale to observe its impact on the end-user and in various social contexts.

Consequently, the presented architectural concept is inspired by kinetic and biomimetic design and aims to be an innovative approach to existing environmental elements, while opening new directions of research through multidisciplinarity, respectively, the proposed collaboration between fields such as architecture, interior and landscape design, robotics and mechanics. 
The main objective of our study was to propose a combination of technical and architectural solutions dedicated to increase energy efficiency in a passive way, with new functional and aesthetic features, easy to integrate in future sustainable buildings.

The secondary objectives are:

- $\quad$ To find and study new materials responsible to external stimuli (temperature, heat or light);

- To design some elementary architectural devices (cells), parts of a more complex passive mesh, capable to be integrated in advanced building structures;

- $\quad$ To use plants for a better technical and architectural comfort, in a self-sustaining eco-building environment;

- $\quad$ To educate architecture and engineering students towards new advanced building solutions;

- $\quad$ To conceive a pilot project setup in order to demonstrate the findings and results. This setup device must be passive in terms of energy consumption;

- $\quad$ To propose some possible technical solutions for future sustainable buildings.

Hygroscopic materials seem to be more appropriate to the aim of this paper. Different paper types are more "green related" materials, simple, and eco-friendly. However, the use of such materials is not suitable in case of civil engineering, for buildings directly exposed to environmental stress (humidity, heat, radiation, wind, etc.). Kapton paper seems, for the instant, a more reliable component, despite the fact that its shape changing properties are not so impressive. Different combination of tapes, assembled in double layered structures could easily improve shape changing as function of temperature. A patent request is pending for these solutions.

The urban environment, in all public spaces, is furnished with pieces with which we interact directly or indirectly. The combination of aesthetics with the functional part, the incorporation of human interaction in the process of the form follows certain functions which are specific to the behavior of models in nature.

All solutions described here could be easily applied to any urban environment or any design context and could be improved function of the specific architectural land-scape.

Smart devices are considered so because they incorporate technology, but, in fact, natural models highlight another type of smartness, by which the action of external agents is assimilated and transformed in favor of organisms, and the entire environment works together, similar to natural systems that work by minimizing accessories/equipment.

The tests performed do not provide enough data for the time behavior of the installation or for the life of the components. The results show small scale functioning systems that use little to no technology to function. In addition, the generated shapes are results of the research process and can be easily adapted at different scales, in different environments and corelated with other materials.

\section{Conclusions}

MODGREW was created as a multidisciplinary bottom-up approach, focused on process methodology and willing to explore new opportunities of design inspired by natural patterns. Geometric study and optimization of shape were among the essential phases of the study, ensuring an alternate, forward-thinking approach toward design disciplines. Function and means of interaction generated shapes, overpassing the methods of nature imitation. Moreover, the physical materialization of the designed geometry involved experimentation with 3D-printing, materials' features and constraints and generated a both digitally and physically innovative model.

The academical importance resides in the potential of experimentation, as research and learning skills, for students in architecture and engineering. A blend of naturally activated mechanisms, human interaction and technology is relevant to the research field. Furthermore, the playfulness of both the modeling process and the actual interaction with a moving installation adds a ludic dimension and curious attractiveness to the idea, which becomes a good reference for future involvement in the project. 
As the process of the real scale materialization of the 3D-printed board with shapechanging lamellae has showed, the physical creation crowns the digital research. Therefore, the MODGREW process leaves room for further research directions and modeling opportunities through the concept of the pyramidal model with planter areas. Materializing it at an urban scale, as the team initially imagined it, would be an astounding victory in the area of eco-friendly, natural, interactive installations, thus the team is eager to both conduct further initiatives regarding it, and to encourage possible external involvement in the future of the concept.

The main effects (or advantages) of the modular green walls are:

- New architectural signature of the building.

- Increased energy efficiency due to active shading and additional active thermal insulation.

- Advanced design in terms of aesthetics and integration of live green elements.

- An interesting didactic case study and a starting point for students in architecture and engineering sciences.

- Improved comfort and stress relief for people living and working nearby such structures.

- $\quad$ Our studies are different from other previous ones in terms of:

- New thermosensitive materials.

- Original architectural elements (both as cell/module and as an ensemble).

- Interactive green elements requiring specific care and maintenance, solved in a sustainable manner.

- Development of a small-scale pilot setup.

- Possible refurbishment projects for existing buildings/indoor and outdoor public spaces.

- Didactic and demonstrative activities for targeted student groups.

There is no single technical or architectural solution which can easily match energy efficiency and aesthetic and functional aspects, at a reasonable cost. Only by combining new architectural elements (new shapes and matrix structures) with new thermo-sensitive materials, as well as integrating plants in biometrical responsive structures, we can obtain an adequate building solution. Some of materials and solutions presented in this paper will be the subject of national and international patent demands, as much as research will be continued.

We can study other types of automation or other variants of the design module, by optimizing the behavior over time by identifying low tech alternatives, reducing the need for maintenance or reducing resource consumption.

Author Contributions: Conceptualization, A.A.A. and A.-D.H.; methodology, I.M.; software, A.-D.H.; validation, I.M., D.G. and O.C.M.; formal analysis, O.C.M.; investigation, O.C.M.; resources, I.M.; data curation, D.G.; writing—original draft preparation, A.-D.H.; writing—review and editing, F.M.F.-I.; visualization, I.M.; supervision, F.M.F.-I.; project administration, A.A.A.; funding acquisition, A.A.A. All authors have read and agreed to the published version of the manuscript.

Funding: This work was supported by research grant GNaC2018 ARUT, no. 1347/1 February 2019, financed by Politehnica University of Timisoara.

Institutional Review Board Statement: Not applicable.

Informed Consent Statement: Not applicable.

Conflicts of Interest: The authors declare no conflict of interest.

\section{References}

1. Benyus, J.M. Biomimicry: Innovation Inspired by Nature; Harper Collins: New York, NY, USA, 1997.

2. Mehaffy, M.; Salingaros, N.A. Design for a Living Planet: Settlement, Science and the Human Future; Sustasis Press: Portland, OR, USA, 2015.

3. Dovjak, M.; Kukec, A. Prevention and control of sick building syndrom (SBS). Int. J. Sanit. Eng. Res. 2014, 8, 41-55.

4. Mohora, I.; Anghel, A.A. Revitalization Proposals for Green Interior Courtyards in the Historical Centre of Timisoara. IOP Conf. Ser. Mater. Sci. Eng. 2019, 471, 082027. [CrossRef] 
5. Bringslimark, T.; Hartig, T.; Patil, G.G. Psychological benefits of indoor plants in workplaces: Putting experimental results into context. HortScience 2007, 42, 581-587. [CrossRef]

6. Coma, J.; Perrez, G.; Burs, G.S.; Urrestarazu, M.; Cabeza, L.F. Vertical greenery systems for energy savings in buildings: A comparative study between green walls and green facades. Build. Environ. 2017, 111, 228-237. [CrossRef]

7. Gunawardena, K.; Steemers, K. Living walls in indoor environments. Build. Environ. 2019, 148, 478-487. [CrossRef]

8. Kaplan, S. The Restorative Benefits of Nature: Toward an integrative framework. J. Environ. Psychol. 1995, 15, 169-182. [CrossRef]

9. Williams, F. The Nature Fix: Why Nature Makes Us Happier, Healthier, and More Creative, 1st ed.; W. W. Norton \& Company: New York, NY, USA, 2017.

10. Manso, M.; Castro-Gomes, J. Green wall systems: A review of their characteristics. Renew. Sustain. Energy Rev. 2015, 41, 863-871. [CrossRef]

11. Schumacher, P. The Autopoiesis of Architecture, Volume I: A New Framework for Architecture; Wiley \& Sons Ltd.: Chichester, UK, 2012

12. Reichert, S.; Menges, A.; Correa, D. Meteorosensitive architecture: Biomimetic building skins based on materially embedded and hygroscopically enabled responsiveness. Comput. Aided Des. 2015, 60, 50-69. [CrossRef]

13. Loonen, R.C.G.M.; Trčka, M.; Cóstola, D.; Hensen, J.L.M. Climate adaptive building shells: State-of-the-art and future challenges. Renew. Sustain. Energy Rev. 2013, 25, 483-493. [CrossRef]

14. Holstov, A.; Bridgens, B.; Farmer, G. Hygromorphic materials for sustainable responsive architecture. Constr. Build. Mater. 2015, 98, 570-582. [CrossRef]

15. Attia, S. Evaluation of adaptive facades: The case study of Al Bahr Towers in the UAE. Proceedings of Qatar Green Building Conference 2016-The Action, Doha, Qatar, 13-15 November 2016; p. 8.

16. Lambertini, A.; Leendhardt, J. Vertical Gardens, Bringing the City to Life; Thames \& Hudson: London, UK, 2007.

17. Anghel, A.A.; Mohora, I.; Preda, A.D.; Giurea, D.; Frigura-Iliasa, F.M. Environmental Tendencies in Modular Green Installations. J. Green Build. 2019, 14, 197-221. [CrossRef]

18. Perini, K.; Ottelé, M.; Haas, E.M.; Raiteri, R. Greening the building envelope, facade greening and living wall systems. Open J. Ecol. 2011, 1, 1-8. [CrossRef]

19. Wagemans, M. Modularity of Living Wall Systems; Delft University of Technology, Faculty of Architecture and the Built Environment, Building Technology Section: Delft, The Netherlands, 2016.

20. Tseng, M.; Wang, Y.; Jiao, R.J. Modular Design. In CIRP Encyclopedia of Production Engineering; Chatti, S., Laperrière, L., Reinhart, G., Tolio, T., Eds.; Springer: Heidelberg/Berlin, Germany, 2019.

21. Anghel, A.A.; Giurea, D.; Milincu, C.; Mohora, I.; Preda, A.; Frigura-Iliasa, F. MODGREW Intelligent Green Walls for Public Areas. In Proceedings of the 9th International Conference on Energy and Environment CIEM 2019, Timisoara, Romania, 17-18 October 2019.

22. Mayrand, F.; Clergeau, P. Green Roofs and Green Walls for Biodiversity Conservation: A Contribution to Urban Connectivity? Sustainability 2018, 10, 985. [CrossRef]

23. Assimakopoulos, M.-N.; De Masi, R.F.; de Rossi, F.; Papadaki, D.; Ruggiero, S. Green Wall Design Approach towards Energy Performance and Indoor Comfort Improvement: A Case Study in Athens. Sustainability 2020, 12, 3772. [CrossRef]

24. Qin, H.; Hong, B.; Jiang, R. Are Green Walls Better Options than Green Roofs for Mitigating PM10 Pollution? CFD Simulations in Urban Street Canyons. Sustainability 2018, 10, 2833. [CrossRef]

25. DuPont ${ }^{\mathrm{TM}}$ Kapton ${ }^{\circledR S}$ ummary of Properties. Available online: https://www.dupont.com/content/dam/dupont/amer/us/en/ products/ei-transformation/documents/EI-10142-Kapton-Summary-of-Properties.pdf (accessed on 5 December 2021).

26. Anghel, A.A.; Milincu, C.; Giurea, D.; Mohora, I.; Hapenciuc, A.D.P.; Frigura-Iliasa, F.M. New Tools for teaching Smart Design. In Proceedings of the ICERI 2019, 12th International Conference of Education, Research and Innovation, Seville, Spain, 11-13 November 2019; Chova, L.G., Martínez, A.L., Torres, I.C., Eds.; IATED Academy: Valencia, Spain, 2019. ISBN 978-84-09-14755-7.

27. Radić, M.; Brković Dodig, M.; Auer, T. Green Facades and Living Walls-A Review Establishing the Classification of Construction Types and Mapping the Benefits. Sustainability 2019, 11, 4579. [CrossRef]

28. Akashdeep, J.; Singh, T.; Singh, S.; Singh, P.; Benipal, N.; Tatro, R.; Thomas, D. Autonomous Hydroponic System; California State University Sacramento: Sacramento, CA, USA, 2020; Volume 24. 